\title{
LA HERENCIA DE UN TEJEDOR VALENCIANO EN EL SIGLO XV. NUEVA EDICIÓN DEL MANUSCRITO DE SEGORBE
}

\author{
THE HERITAGE OF A VALENCIAN WEAVER IN THE $15^{\text {th }}$ CENTURY: \\ NEW EDITION OF THE SEGORBE MANUSCRIPT
}

Germán NAVARRo ESPINACH y Joaquín APARICI MARTí Universidad de Zaragoza / Universitat Jaume I de Castelló gnavarro@unizar.es / japarici@uji.es

\begin{abstract}
Resumen: Este trabajo analiza la administración de la herencia que dejó a sus cuatro hijos menores de edad un tejedor de Segorbe a cargo de otro tejedor que actuó como tutor de los mismos. Los principales asuntos registrados durante los años 1434-1440 en el documento completo de la tutela que se transcribe son la partición y subasta de los bienes entre la viuda y sus cuatro hijos, y los ingresos y gastos detallados, correspondiendo algunos de ellos a la gestión de una viña conservada por dos hijas hasta la extinción de la citada tutela al estar una de ellas casada y haber fallecido la otra.
\end{abstract}

Palabras clave: artesanado, familia, muerte, herencia, infancia, tutela, Segorbe, siglo XV.
Abstract: This work analyzes the administration of the inheritance that a weaver from Segorbe left to his four minor children by another weaver who acted as guardian of the same. The main matters recorded in the complete document of the guardianship that is transcribed during the years 1434-1440 are the partition and auction of the assets between the widow and her four children, and the detailed income and expenses, corresponding to some of they to the management of a vineyard kept by two daughters until the expiration of the mentioned guardianship when one of them was married and the other had died.

Key words: crafts, family, death, heritage, chilhood, guardianship, Segorbe, $15^{\text {th }}$ century. 


\section{Una herencia bajo tutela en una ciudad del interior}

La ciudad de Segorbe se sitúa en el sur de la actual provincia de Castellón en la comarca interior del Alto Palancia dentro de los límites del antiguo reino de Valencia. Su archivo municipal conserva un manuscrito singular para conocer muy de cerca el mundo de los artesanos medievales (Guerrero, 1986: 72, lám. X; Navarro y Aparici, 1997). ${ }^{1}$ Se trata del libro memorial y contable de la tutela que gestionó Juan Fretero, un tejedor vecino de dicha ciudad, en calidad de administrador de los bienes que heredaron los hijos menores de otro tejedor de nombre Pedro Martínez, vecino también de Segorbe. Comienza el 25 de febrero de 1432 con el inventario de bienes posterior a la muerte de Martínez y concluye en fecha 3 de mayo de 1440 con la entrega del dinero restante que quedaba de la herencia a Catalina, una de las hijas del difunto que ya estaba casada. Dicho manuscrito se compone de 78 hojas de papel, tamaño 225 x 115 $\mathrm{mm}$, foliadas con lápiz en los ángulos inferiores externos de cada hoja. Está redactado en catalán con injerencias del aragonés y algunas expresiones formularias en latín. La escritura alcanza hasta el recto del folio 53, quedando las restantes hojas en blanco. La estructura de contenidos es la siguiente, como puede observarse con detalle en la transcripción completa del texto que presentamos en el apéndice:

- Título $(\S 1)$.

— Partición de la herencia entre la viuda y sus cuatro hijos ( $\$ 2$ a 80).

- Subasta de bienes muebles ( $\$ 81$ a 101).

— Ingresos o reebudes hasta 1439 ( $\$ 102$ a 148).

- Gastos o dates desde el comienzo de la tutela hasta el 1 de enero de 1434 ( $\$ 149$ a 181).

— Partición de bienes entre los cuatro hijos ( $\$ 182$ a 195).

— Ingresos ( $\$ 196$ a 206) y gastos ( $\$ 207$ a 274) correspondientes a una viña conservada por dos hijas hasta 1440 , cuando se produjo la extinción de la tutela al estar una de ellas casada y haber fallecido la otra.

No perdura la cubierta del volumen puesto que el pergamino original que cumplía dicha función era un censo de 1306 que ahora se cataloga aparte (Guerrero, 1986: 66). Al día de hoy solo conocemos un manuscrito similar del

1 Archivo Histórico Municipal de Segorbe, Documentación Ajena, Serie Varia, nº 256. 
siglo XV en el reino de Valencia. Se trata de la contabilidad de un notario de la villa de Sueca que administró los bienes de un huérfano durante los años 1412-1427 y que fue hallada inserta dentro de un volumen de diversas cuentas municipales (Guinot y Furió, 1980). ${ }^{2}$ Según la foralidad valenciana, entre las diversas funciones que se atribuían a las autoridades locales estaba la de velar por la correcta administración de las tutelas entre los habitantes de sus poblaciones. Es por esa razón por la que este manuscrito está en el Archivo Histórico Municipal de Segorbe. De hecho, cuando se producía la muerte de un vecino con hijos menores de edad correspondía al municipio designar a un pariente del difunto, mayor de 20 años, para hacerse cargo de la gestión de los bienes heredados hasta que cumplieran la mayoría de edad fijada en esos 20 años, siempre y cuando el padre o la madre no hubieran dado indicaciones específicas al respecto en sus últimas voluntades. En ocasiones, ante la ausencia de parientes, la responsabilidad recaía directamente en funcionarios de la corte local o en un notario, o ambas cosas a la vez, como sucede en el caso de Sueca. La obligación del tutor era la de rendir cuentas de su gestión ante el municipio y para ello debía anotar sucesivamente las continuas incidencias de su administración, bien junto a la contabilidad oficial como ocurre también en Sueca, o incluso mediante la confección de un cabreve en el plazo máximo de tres años desde que hubiera finalizado la tutela, tal y como sucede en el manuscrito de Segorbe que aquí nos ocupa. De ese modo, si el tutor había realizado una mala gestión los herederos podrían denunciarle (Guinot y Furió, 1980: 12 , n. 2 y 3).

De un modo o de otro, y por los años de la primera mitad del siglo XV, la familia del tejedor Pere Martínez vivió en la villa más grande de las comarcas interiores del centro-norte del reino medieval de Valencia. La sede episcopal de Segorbe acumulaba una población mixta de cristianos con un destacado arrabal mudéjar y una reducida pero muy activa comunidad judeoconversa. Las rentas que percibía la monarquía de esta ciudad muestran una dualidad que se asemeja bastante al caso propio de la ciudad de Xàtiva. Casi la mitad eran rentas fijas con una fuerte pecha más elevada en la morería que en la villa cristiana a pesar del menor contingente humano. A éstas se unían otros conceptos fijos anuales como el herbaje, los censos pequeños sobre monopolios, las casas y las tierras, y una heredad establecida a censo - la almunia del se-

2 Véase de igual modo la edición de un manuscrito de cuentas y asuntos familiares que redactó un notario de la ciudad de Valencia también en el siglo XV (Cruselles, 1986). 
ñor- que elevaban estos ingresos fijos a un $60 \%$ del total. Mientras tanto, entre las rentas variables y arrendadas periódicamente destacaba como siempre el tercio diezmo, en este caso con una proporción muy inferior a la habitual (18\% de los ingresos totales). En cambio, el conjunto de monopolios resulta mucho más destacado que en otras villas similares como fuente de ingresos, al estar en régimen de arrendamiento temporal y pertenecer sobre todo a los mudéjares. Estos monopolios gravaban en buena parte actividades artesanales que iban más allá del consumo alimentario, esto es, carnicerías, horno de la morería, tintorería, torcedor de la cera y diezmo sobre producción cerámica, alcanzando un 17\% de las rentas de la corona (Guinot, 1992: 616617; García Edo, 1987; Cervantes, 1998).

Los censos del morabatín referentes a Segorbe con su arrabal, morería y judería registran una población fiscal en torno a los 700 fuegos durante el primer tercio del siglo XV. La propia ciudad en donde radicaba la sede del obispado y del poder municipal — donde tenían su casa los Martínez-sumaba más de 275 fuegos, sin olvidar además el colectivo destacado de clérigos y privilegiados o las muchas personas pobres que debieron quedar fuera de los registros fiscales. Arrabal y aljama mudéjar rondaban también los 200 fuegos cada uno, frente a una judería de menguantes dimensiones demográficas. Esa aglomeración urbana se completaba con las vecinas comunidades rurales de Cárrica, Torcas, Geldo y Navajas, en proximidad también dentro del mismo valle del Alto Palancia con núcleos como Jérica, Bejís, Altura o Castellnou. Y frente al estancamiento aparente en la cantidad 'oficial' de población se descubre cierta tendencia clara a la profunda movilidad social y al recambio constante en la estructura interna de la población. El mismo ambiente socioprofesional detectado a través de la fiscalidad ofrece la imagen inicial de un activo centro artesano. Al menos 77 personas censadas en el morabatín desempeñaban 32 ocupaciones diferentes, 47 de ellas con oficios artesanales y de éstas, 16 vinculadas a la industria textil: 7 tejedores, 6 pelaires, 2 tintoreros y 1 pentinador o peinador (Arroyo, 1969; Guerrero, 1984).

Esos indicios sirvieron de acicate para profundizar en el estudio de Segorbe y el territorio adyacente a través de la documentación notarial y judicial conservada en los archivos locales y confirmar el importante desarrollo artesanal de la ciudad, en particular, así como su dispersión capilar en la comarca, con la preeminencia de la manufactura textil y del cuero por delante de la cerámica, el metal, la madera, la cera, etc. Así, para el siglo XV y en el ámbito textil, se han localizado en la ciudad un total de 253 pelaires, 64 tejedores, 23 
tintoreros y hasta otros 50 profesionales relacionados con dicho sector artesanal, así como una corporación de pelaires, varios patios de tirador, dos molinos batanes y tres casas de tintes y, también, un activo comercio de lanas y pastel. Además, se documenta la presencia de artesanos entre los miembros de la oligarquía urbana desempeñando algunos oficios municipales. Sin embargo, el despegue se había producido en los años sesenta de la centuria anterior. Ocho profesionales, dos molinos batanes, una tintorería, y también el viaje de un representante del oficio de pelaires para ver las normativas de los aprestadores y tintoreros de la capital del reino ponen de manifiesto que la producción de paños comenzaba a ser importante. En los años inmediatamente siguientes se documentará también a otros 17 profesionales. Ello cabe unirlo en el ámbito comarcal con la presencia de otros 12 pelaires a fines del Cuatrocientos en el vecino lugar de Viver y con la mención a un molino batán. En Bejís se documentan 5 pelaires en la segunda mitad del XV, además de otro molino batán. En Altura hubo al menos 3 tejedores y 6 pelaires más y otro batán. Y, por último, en Jérica a lo largo del siglo XV se documentan 44 pelaires, 7 tejedores, 2 tintoreros y otro molino batán (Aparici, 2001 y 2015).

\section{La administración de los bienes}

El origen de este manuscrito de Segorbe, llamado en su comienzo libro memorial, cabreve o repertorio por parte del tutor responsable del mismo, nació de la última voluntad del tejedor Pedro Martínez plasmada en el testamento que redactó Ramón del Ort en 1432, notario cuyos protocolos no hemos podido localizar. De hecho, no consta su nombre en el listado de protocolos notariales custodiados en la catedral de Segorbe, ni en los fondos de los archivos del Colegio del Patriarca o de la sección específica del Archivo del Reino, ambos en la ciudad de Valencia. Dicho notario Ramón del Ort está identificado como jurado y clavario de cuentas en la documentación municipal y en nuestro manuscrito se le designa también como juez de la ciudad (\$182). Estaba casado con Leonor Vicent, hija de un mercader converso de Segorbe. La última noticia en que ha sido localizado es cuando pagó 2.000 sueldos por una tacha impuesta a los conversos de Segorbe en agosto de 1488 (Aparici, 2001: 196).

En el citado testamento del tejedor, tal y como explica la intitulación del propio cabreve, se asignó un tutor para administrar la herencia percibida por los cuatro hijos del difunto y de su esposa Catalina Gómez: Bartolomé, Isabel, Teresa y Catalina (§1). La supervisión pública del proceso quedó en manos de 
Juan de Moros, justicia de Segorbe, el cual delegó esa tarea en dos jueces asignados para proceder al reparto de los bienes. En ese sentido, durante la partición inicial constan como tales los honrados Martín de Alloza y Gil de la Cerda, vecinos de Segorbe (§3), sin embargo, en la segunda partición posterior que se producirá entre los hijos serán Gil de la Cerda y Domingo El Toro (§182). Así, pues, hubo una primera división de bienes a partes iguales entre los menores y su madre, la viuda del tejedor, en virtud del régimen matrimonial de germanía con el que se casó (§183). La germanía era un contrato no foral basado en la costumbre de que cada uno de los esposos fuese propietario de la mitad de los bienes habidos durante el matrimonio, como sucede en este caso. Si sólo se compartía lo obtenido durante el matrimonio, pero cada uno mantenía la propiedad individual de lo aportado, se denominaba germanía de aumentos (germania d'augments), mientras que la comunidad de bienes de todo, es decir, de lo aportado y de lo obtenido, se conocía como germanía plana. Ese modelo era diferente del tradicional contrato de dote matrimonial con el que acostumbraban a casarse la nobleza y la burguesía valencianas. La germanía era, por lo tanto, un pacto libre entre los esposos que normalmente se practicaba entre el campesinado o el artesanado, fortaleciendo la tendencia hacia un mayor equilibrio entre lo que aportaban ambos cónyuges y cimentando, además, el núcleo familiar restringido (Iradiel, 1986: 239, n. 38).

La primera partición de la herencia fue ejecutada, pues, por el tejedor Juan Fretero como tutor, acompañado de otro tejedor de nombre Domingo El Toro que actuaba además en calidad de albacea (marmessor) o ejecutor del testamento (§2). La parte de la herencia correspondiente a los cuatro hijos, responsabilidad de la tutela para el futuro, acabó valorada finalmente en 37 libras, 15 sueldos y 8 dineros de moneda valenciana ( $(148)$. Una libra valenciana equivalía a 20 sueldos y 1 sueldo a 12 dineros. El manuscrito explica con claridad el procedimiento posterior a la partición de bienes entre la madre y los hijos. El tutor debía elaborar un informe sobre su gestión hasta el 1 de enero de 1434 con el objeto de efectuar una segunda división otra vez en partes iguales, pero ahora entre los cuatro menores ( $\$ 183$ a 190). Al respecto, el tutor compró un libro por el precio de 6 dineros a cuenta de los bienes tutelados $(\S 150)$. Después contrató los servicios de un profesional de la escritura para redactarlo, que fue el mismo notario del testamento paterno, el citado Ramón del Ort, a quien le entregó los diferentes documentos y albaranes que tenía desde el comienzo de su gestión para que empezara a redactar el memorial de la tutela. Además, los jueces o árbitros del proceso indicaron al tutor qué debía hacer 
para tomar las decisiones más importantes, tal y como se desprende de la justificación que se da a la hora de vender los bienes muebles de los menores, no sólo para evitar así su progresiva devaluación sino también para facilitar el segundo reparto en dinero, gracias a la liquidación de dichos bienes en subasta pública $(\S 184)$.

El tutor realizó dos subastas en presencia del mismo notario Ramón del Ort y otras tres subastas más para arrendar una viña situada en Navajas - cuyo valor se estimaba en 5 libras - y una hanegada de cereal localizada en la partida de Utrillas de la huerta de Segorbe valorada en 10 libras. Pagó censos, pecha, monedaje, salarios de notarios, corredores y otros diversos. Llegado el momento de la segunda partición, los jueces comprobaron los ingresos (37 libras, 15 sueldos, 8 dineros) y los gastos (6 libras, 10 sueldos, 6 dineros) detallados en el memorial con todos los albaranes adjuntos, separando por su trascendencia posterior aquellos gastos de alimentación (2 libras, 18 sueldos, 2 dineros) que fueron necesarios para los hijos más pequeños, Bartolomico e Isabelita (\$189). El pago a su madre por mantener a ambos niños durante 20 meses desde abril de 1432 a enero de 1434 fue de 21 libras a razón de 12 sueldos por mes por lactancia del niño y 4 dineros al día por manutención de la niña. Y para saldar parte de esa cantidad adeudada a la madre se le entregó la hanegada de cereal de Utrillas. El balance positivo de las cuentas en 1434 había sido de 31 libras, 2 sueldos y 2 dineros que repartidos en cuatro lotes iguales fueron 7 libras, 15 sueldos, 6 dineros y meaja para cada uno. Los más pequeños, Bartolomico e Isabelita, sumaban juntos 15 libras, 11 sueldos y 1 dinero, pero los 20 meses de su mantenimiento (las 21 libras) y otros gastos añadidos redujeron a cero su participación en la liquidación final de las cuentas de la tutela (§195). Mientras tanto, las dos hijas mayores, Catalina y Teresa, esta última llamada también Beleta, ${ }^{3}$ percibieron la viña de Navajas junto con 11 libras, cantidad de dinero que se aconsejó al tutor que la invirtiera en la compra de un censal ( $\$ 194$ y §206). Además, como las niñas eran menores de 20 años de edad y todavía no estaban casadas, el tutor tenía obligación de continuar con otra nueva administración (§196).

3 Teresa, o Teresuca, comienza a ser denominada Beleta por el tutor a partir del f. 42r (§196) cuando su hermana Isabeleta deja de ser responsabilidad de la tutela. Este hecho podría sugerir que Teresa hubiera muerto y su parte fuera ahora de su hermana menor, pero no fue así. Si se observa atentamente el f. 20r con ciertas cuentas insertas de 1436 sobre la viña de las dos niñas después de la segunda partición de 1434, allí se sigue hablando de Catalineta y Teresuca. En defintiva, Beleta era un apelativo familiar del tutor para designar a Teresa, una vez que cualquier confusión con el nombre de su hermana Isabelita ya no podía producirse. 
A partir de ese momento, por lo tanto, el manuscrito se centra casi de modo exclusivo en el cuidado de la viña de Navajas, anotando todos los beneficios de su explotación, los diversos pagos del censo cargado sobre la propiedad, y los costes del cultivo, desde las propias faenas de vendimia hasta el proceso de extracción del vino. El final de la tutela se produjo ocho años después de su inicio, cuando el 3 de mayo de 1440 cobró su salario el tutor y entregó un capital de 5 libras a Catalina y a su marido Miguel de Carrión, tanto por la parte que le correspondía de la herencia de su padre como por la de su hermana Teresa ya difunta (\$274). Agrupando cifras para un balance general de las cuentas, el capital de salida en 1432 tras la partición con la madre - 37 libras, 15 sueldos, 8 dineros - (\$146) se había reducido en 1434 a menos de la mitad -15 libras, 11 sueldos, 1 dinero-, correspondiendo ya solamente a Catalina y Teresa, puesto que Bartolomé e Isabel habían gastado su parte en manutención propia (§180). Así, pues, la administración se cerró en 1440 con un finiquito todavía menor: 5 libras (\$274). Entre los gastos más importantes después de la segunda división estuvo el propio salario del tutor valorado al cierre de las cuentas en 3 libras (\$273).

\section{Perfil social y recursos económicos de la familia}

El difunto tejedor Pedro Martínez había asegurado más allá de su muerte la perduración material de sus hijos y de su viuda. Era un pequeño artesano autónomo con propiedades agrícolas. La familia era la célula social que controlaba y distribuía las trayectorias vitales de sus componentes y les permitía perpetuarse de una generación a otra. En este caso, la dimensión del grupo doméstico que nos ocupa aparece restringida a la pareja, un bebé de entre 6 y 8 meses de edad (\$8) y tres niñas menores de 20 años. Una comunidad de 6 personas que, tras la muerte del padre en 1432, con la separación de bienes de la viuda, la pérdida de su parte por los dos hijos más pequeños en 1434 y la muerte de Teresa antes del cierre de la tutela en 1440, sólo parece tener como único fruto de promoción social el matrimonio de su hija Catalina. Fuera de la administración de la tutela, no sabemos si la viuda contrajo segundas nupcias y si los niños pequeños lograron superar las altas tasas de mortalidad infantil de la época para entrar definitivamente en la vida con el aprendizaje de un oficio para él y el servicio doméstico para ella en el hogar de familias más solventes, como solía ser costumbre (Navarro, 2004; Aparici y Navarro, 2010). Seguramente, Teresa debió realizar otro servicio doméstico hasta su 
fallecimiento, tal y como ha sido posible documentar en el caso de Catalina, de lo que se deduce que la inexistencia de gastos sobre su alimentación y vestido en la gestión de la tutela en su caso fuese debido a que vivían con esas familías de acogida, que las alimentaron y vistieron a su cargo y se ocuparon de ellas hasta llegar a la edad del matrimonio, en el caso de Catalina, o hasta su muerte en el caso de Teresa. Respecto a Catalina, su padre falleció antes del 25 de febrero de 1432 y el tutor la colocó a ella como sirvienta el 20 de mayo de dicho año. ${ }^{4}$ Fue contratada por tiempo de 6 años como sirvienta del pelaire Marco Vida, vecino de Segorbe. Recibiría 220 sueldos al final del contrato más las ropas acostumbradas. Teniendo en cuenta que los contratos de servicio femeninos tendían a finalizar cuando las contratadas estaban preparadas para el matrimonio, por ejemplo, en torno a los 18 años, y que el tiempo del contrato se calculaba de acuerdo con la edad que tenía la moza en el momento de la formalización del mismo, podemos suponer que, si el de Catalina fue por 6 años, en el momento del óbito del padre la niña debía tener unos 12 años. La mayoría de edad legal para protagonizar actos jurídicos en la Corona de Aragón se situaba a partir de los 12-14 años. Los contratos o las renovaciones de los mismos a veces las firmaban las propias mozas por cumplir ya con dicha mayoría legal.

Antes de la desaparición del cabeza de familia, la economía doméstica de los Martínez en ese contexto histórico dibuja una doble fuente de ingresos: la explotación de cultivos agrícolas y la actividad manufacturera. La segunda vertiente será la que dé verdadera personalidad social al tejedor Pedro Martínez dentro de los esquemas de la jerarquía urbana local, al poseer conocimientos de un oficio o saber técnico que había recibido cuando era joven, seguramente mediante el aprendizaje durante varios años en casa de otros tejedores o tal vez con su padre. La pertenencia manifiesta a la cofradía de san Blas (§164) le encuadraba en otro marco de solidaridad vecinal que completaba más su perfil cultural inserto dentro de la mentalidad cristiana dominante (Hinojosa, 2005). Sus ropas y vestiduras fueron vendidas por los ejecutores del testamento para cumplir las pías causas que estableció en el mismo a la vez que para afrontar los gastos de su propio funeral (\$71).

Martínez poseía varios medios de producción básicos que desaparecieron rápidamente en las subastas de bienes de la tutela, sin posibilidad alguna de recambio generacional en el oficio a cargo de los hijos, ni interés mínimo de 
apropiación por parte de la viuda. Aquellos útiles de trabajo consistían en un urdidor de madera (§13), un torno para hacer canillas (§14), unas devanaderas con sus pies $(\S 15)$, un par de pintes para cardar lana $(\$ 57)$ y un telar con sus arreos (\$71). También almacenaba un volumen modesto de materias primas, especialmente estopa, cuestión que sugiere la especialización técnica de Martínez como tejedor de paños comunes de lana y mezclas: 7 libras y 4 onzas de hilaza de estopa cocida, 6 libras y media de hilaza de estopa cruda, y libra y media de estambre blanco ( $\$ 32$ a 34). En ese sentido, no es posible conocer por la tutela ningún dato sobre el nivel y destino de su producción textil. En hipótesis, los tejidos producidos por Martínez se encuadrarían en el conjunto de paños que satisfacían la propia demanda local-comarcal, y se constituían en fuente de buenos ingresos a corto plazo. El muestreo obtenido en los protocolos notariales sobre los paños producidos en la comarca del Alto Palancia nos permite suponer que en esta zona predominaban los paños de calidad medio-baja, generalmente crudos, morenos o con un simple teñido de pastel, bajo la denominación habitual de palmellas o cordellates (Aparici, 2001: 61-63 y 200).

El perfil del difunto sería similar tal vez al de su compañero de oficio, el tejedor Juan Fretero, tutor de la herencia, documentado entre 1401 y 1445. Aparece confeccionando y vendiendo paños de lana, o vendiendo un telar al también tejedor Miguel de Bernabé. Por su parte, Pedro Martínez, el difunto tejedor, se documenta en el censo del monedaje de 1421, y un mes antes de su fallecimiento, junto a su esposa Catalina Gómez y junto al tejedor Domingo Pérez y su mujer Pascuala, vendiendo a un beneficiado de la catedral 66 sueldos y 8 dineros censales cargados sobre una viña que poseían por el precio de 800 sueldos. El tejedor Domingo El Toro, albacea testamentario y juez de la tutela, está documentado también entre 1432 y 1480. Casado con Juana Villel, cargó un censal, fue fiador en el juramento del hostalero Juan de la Cambra, y en 1480 figura como arrendatario de las imposiciones mayores de Segorbe. Con todo, son artesanos como el pelaire Juan Aragonés, mencionado como colector del monedaje en el memorial, quienes ofrecen un perfil social de mayor envergadura durante los años 1414-1458: consejero municipal, procurador de los pobres vergonzantes, varios aprendices a su servicio, arrendador de casas de su propiedad, veedor del oficio de pelaires, arrendatario de la primicia, prestamista, protagonista de compraventas de lana y encargos de trabajo a otros artesanos, propietario de la mitad de un batán y, por último, padre de cuatro hijos que alcanzaron cierta promoción social: Miguel, maestro en artes y clérigo, Juan y Mateo, bajadores de paños, y Antonio, pelaire (Aparici, 2001: 136, 161, 168 y 184). 
Por otro lado, téngase presente que la administración de la tutela no muestra todo el patrimonio familiar de los Martínez, puesto que los bienes inmuebles que correspondieron a la viuda no fueron incluidos en la administración de la misma:

La part e mitat dels quals pertanyents als dits pubils entreguament és ací scrita et anotada, et encara la part pertanyent a la dita llur mare dels béns sehents per evitar frau com la sua part dels béns movents no haje volgut ací ésser continuada per tolre despeses. $(\$ 12)$.

Es de suponer que la viuda seguiría viviendo en la casa familiar, quizás en régimen de alquiler, ya que ésta no se menciona como propiedad inmueble, quedándose allí la otra mitad del mobiliario. Lo único cierto que se descubre sobre el hogar es la existencia de un celler o espacio donde elaboraban y guardaban el vino mediante diversos recipientes de madera y arcilla (vaxells de fusta e terra): una cuba grande con capacidad para 106 cántaros ( 1 cántaro = 10,27 litros), otra cuba más pequeña bien cuidada y preparada (una cubeta maresa), 3 jarras de 10 cántaros cada una, 7 jarras de 4 cántaros, 1 jarra de 2 cántaros, y además tres cubos para la vendimia (hun poal et dos perolls de portadores). Su valor global acabó estimado en 5 libras para la cuba grande y 2 libras, 6 sueldos y 6 dineros para los otros recipientes, permaneciendo en la casa en poder de la viuda, quien a cambio restituyó la mitad de su valor en moneda de cuenta a los menores ( $\$ 69$ y 70) (Navarro, 2005). Sin duda, la extracción de vino era una importante fuente de ingresos más allá del autoconsumo. El cúmulo de propiedades agrícolas de la familia en la huerta de Segorbe en el momento de la primera partición de bienes era de dos viñas de extensión desconocida y siete hanegadas de cereal: una viña en la partida de Navajas (valor estimado en 5 libras), otra viña en la partida de Lagunas (comprada por 20 libras mediante carga de censal), 5 hanegadas de cereal en la partida de El Campo (valor estimado en 5 libras) y 2 hanegadas de cereal en la partida de Utrillas (valor estimado en 10 libras) (\$72 a 80).

Consta también cierta deuda de los cónyuges al hornero Juan Ferrández por una comanda de 8 libras y 10 sueldos que habría de saldarse a partes iguales mediante la venta del vino almacenado en la cuba según decidieron los jueces:

[...] per tant havem jaquit lo vi qui és en la dessús mencionada cuba per partir en axí que quant aquell dit vi se vendrà sia venut per lo dit tudor e curador et per la dita Caterina Gómez. (\$79) 
Tanto la viuda como los menores tendieron a la explotación preferente de las viñas. De hecho, la madre no conservó los medios de producción textil de su marido, pero sí los diversos recipientes de la bodega o celler. Recordemos que el tutor terminó por gestionar la viña de Navajas como propiedad única de las dos hijas supervivientes a la segunda partición, frente al deterioro de la hanegada de Utrillas que también al inicio tardaría más en encontrar arrendador (§191). Las cuentas de la tutela sobre la hanegada de Utrillas en propiedad franca (como las de El Campo), solamente recogen la venta de media cosecha perteneciente a los menores en base al régimen de explotación a medias ( $a$ mitges), a lo que obligó la falta inicial de un arrendatario: 15 barchillas de cebada ( 1 barchilla = 16,6 litros) y medio cahíz de maiz ( 1 cahiz = 201 litros $)$ por precio de 32 sueldos y 4 dineros en 1432, deducida la barchilla y la paja por la mitad de los costes de segar y trillar ( $\$ 134$ a 135). A ello se sumaba el ingreso de 17 sueldos anuales por la pensión del arriendo para tres años (§9).

Mientras tanto, la viña de Navajas se explotaba mediante un contrato de enfitéusis con 1 libra y 1 sueldo anuales de luísmo y fadiga, que siempre pagó la tutela incluso durante el arriendo - se desconoce el régimen explotación de la de Lagunas. Las cuentas ofrecen numerosos datos disponibles sobre el cultivo que recuerdan bien al ejemplo de la administración de aquella viña de la tutela de Sueca, cuya extensión tampoco se conocía, aunque se estimaba superior a las 10 hanegadas (Guinot y Furió, 1980: 13-15). La parcela de Navajas fue arrendada durante los tres primeros años del tutelaje (1432-1434) con una pensión anual de 2 libras y 9 sueldos, pasando después en 1435 a la explotación directa por el tutor hasta el finiquito de 1440 (§103-128 y §230273). El balance general del vino vendido por la explotación directa de Navajas fue de 14 cántaros en 1435 (1 libra y 6 sueldos), 50 para 1436-1437 (2 libras y 10 sueldos), 18 en 1438 (1 libra y 4 sueldos) y 16 en 1439 (1 libra y 4 sueldos). El precio de venta oscila entre los 12 y 16 sueldos por cántaro. El cabreve ilustra con claridad cómo se desarrollaba la cadena de producción con las faenas que encargaba el tutor, idénticas a las que describe la contabilidad de Sueca. Por ejemplo, el trabajo inicial era el cavado, realizado por 12 o 15 peones a salario de 2 sueldos y 6 dineros cada uno y con vino y pitanza (ab vi e pitança). La vendimia o recogida de la uva estaba a cargo de uno o de dos hombres según los años, con un salario de 1 sueldo y 6 dineros, incluida la comida. A continuación, las cargas de vendimia se acarreaban hasta el lugar donde se elaboraba el vino, alquilando también un par de portadoras o canastas que se ponían a lomos de un animal, pagando otro salario que, a 
veces, era sumado al de un vendimiador único que hacía ambas operaciones ( 2 sueldos). Para terminar, se alquilaba una cuba (5 sueldos) que se fregaba al terminar el pisado de la uva ( 3 dineros) y alguna jarra (1 sueldo) además de agua para la elaboración. El ciclo anual concluía con la poda de sarmientos y otras faenas como el riego de la tierra y el cuidado de la acequia, operaciones que requerían como mucho tres hombres durante tres jornadas de trabajo (6 sueldos y 8 o 9 dineros de coste). La fase misma de extracción del vino, junto con los cuidados finales del cultivo, tuvieron poco protagonismo entre los equitativos costes de la cadena productiva. El gasto anual de la viña era alto aún dejando aparte lo que se pagaba al año de luismo y fadiga (1 libra y 1 sueldo) o la pecha por la tierra (de 3 a 4 sueldos). El balance de inversión en cultivar y vendimiar variaba sobre las 3 libras y 2 o 5 sueldos en 1435-1436 para bajar hasta 1 libra y 3 dineros o 5 sueldos en 1437-1439, por haber prescindido de la peonada para cavar, concepto que elevaba bastante el gasto total. En verdad, la explotación directa resultaba claramente deficitaria frente al sistema de arriendo que se practicó al principio, y de ahí se desprende el interés del tutor por encontrar un arrendador y evitar la gestión personal. La posesión de una viña por un artesano no implicaba por tanto el trabajo directo del mismo en la tierra, sino que más bien servía en determinados momentos como una base de ingresos que le permitía centrarse en su taller artesanal e incluso cobrar alquileres por el uso de los recipientes para la extracción de vino que poseía en la bodega. Esto matiza bastante aquella teoría que plantea siempre el trabajo artesano como complemento idóneo del trabajo agrícola, e introduce una reflexión más profunda sobre el universo de las economías domésticas de la época.

En ese sentido, un ejemplo de explotación similar encontramos años más tarde en la localidad cercana de Jérica. En 1489 el pelaire Martín Romeyo y su esposa Beatriz arrendaron al pelaire Domingo Millán unas casas en la calle mayor frente al muro del lugar. En su interior destacaban varios recipientes en la bodega, a saber, un cubo de 700 cántaros, otros 5 cubos de 70, 120, 100, 110 y 170 cántaros respectivamente, 2 jarras de 30 cántaros cada una, y una cuba de 8 cántaros. Llevaron a cabo el arriendo de 6 peonadas de viña en la huerta de Jérica en la partida de Tosquillas, 2 peonadas de viña en La Foya y 25 peonadas de viña en Novaliches. El contrato de arrendamiento se estableció por un período de 5 años a razón de 160 sueldos anuales. También sabemos que en 1498 poseía en propiedad franca una viña en la partida de Perdiguera, que vendió por 320 sueldos. El pelaire Domingo Millán era un artesano del sector 
textil, al igual que el difunto Pedro Martínez, y lo documentamos comprando y vendiendo lanas y paños de tipo palmella. ${ }^{5}$

\section{Conclusiones}

El cabreve gestionado por el tejedor Juan Fretero con la asesoría de los jueces y con la ayuda instrumental del notario-escribano era la concrección material de una racionalidad económica. Todo un esquema consciente de reglas sociales, elaboradas y aplicadas de acuerdo a las normas específicas del 'buen' y del 'mal' uso de los bienes para conseguir la superviviencia del capital heredado y la proyección social de los menores beneficiarios (Godelier, 1989; Iradiel, 1993: 37). Resulta evidente una vez más que un individuo o una familia nuclear no pueden producir en solitario ni de forma duradera sus propias condiciones materiales de existencia. Necesitan cooperar con cierto número de otros individuos o familias para hacerlo, y esa cooperación es diferente según el contexto social de unos y otros. El manuscrito estudiado descubre cómo se impone la pertenencia a una misma comunidad, bien de profesión (entre tejedores) o bien de vecindario (Segorbe), para actuar solidariamente (tutor, albacea, jueces) y reproducir las condiciones de existencia del vecindario (Navarro, 2005).

El memorial se convierte así en un registro escrito que sigue de manera sistemática las variaciones del patrimonio familiar. No imita aquel modelo mercantil clásico de contabilidad a partida doble para las empresas (debe y haber), sino que recoge las cuentas especificando los conceptos en dos series paralelas de ingresos y gastos (rebudes $i$ dates), claramente pensado por un artesano-labrador a quien parecen interesar más los detalles de los costes de la producción agrícola que el cálculo rápido de beneficios. Además, el recurso al notario con escritura homogénea en todo el libro no parece evidenciar el analfabestismo de un tutor imposibilitado de valerse por sí mismo que efectúa la delega gráfica. Más bien debió existir cierto afán de rigor en la tarea encomendada y ello llevó a recurrir a los servicios del notario, especialista en escribir, pero sobre todo en diseñar el correcto seguimiento de la estructura interna del cabreve acorde a los formularios notariales al uso. El tejedor que actuaba de tutor ya debía estar bastante acostumbrado al contac- 
to con la escritura por una finalidad eminentemente práctica desde la gestión misma de su producción artesanal para el mercado. Aquí sólo ejectuó, organizó y compiló albaranes justificativos de las cuentas (en pública forma o no) para que el notario redactara el informe de gestión a instancia totalmente privada ( $\sin$ fe notarial) con objeto de ofrecer una rigurosa administración (Cruselles, 1989; Igual, 1992).

El objetivo real del libro de Fretero era representar, interpretar, organizar o legitimar con estrecho consenso de la comunidad (notariado y justicia civil) la supervivencia ideal y material de cuatro niños a la muerte de su padre. Acción que en último término se balanceaba entre una mentalidad medieval que busca la conservación del estatus de grupo que poseían los hijos de Martínez en los esquemas de la jerarquía urbana del siglo XV, y una mentalidad moderna que se preocupaba por la inversión más adecuada para la obtención de un balance positivo en la tutela. Sea como fuere, el sentido final fue la reproducción misma del sistema de valores reinante en su ambiente social. De ahí se comprende la necesidad de controlar ritualmente la economía doméstica con las nuevas posibilidades que ofrecían sus capacidades productivas, y que pasó a ser lo que diferenciaba y oponía los intereses de los menores y de la madre, lo que hacía actuar al tutor a la consigna de una mejora para todos y siempre al servicio del interés general, legitimando por tanto las jerarquías y las diferencias de salida entre los unos y los otros en la vida. En defintiva, las elecciones efectuadas por los jueces y por el tutor en relación al futuro de los hijos de Martínez estaban limitadas por el abanico de posibilidades que correspondían al volumen y estructura del capital heredado del padre, es decir, por su ubicación en la estructura de clases en la ciudad de Segorbe hacia mediados del siglo XV. La labor de la tutoría consistió, pues, en conservar y, en todo caso, aumentar el patrimonio con diversas estrategias de reproducción o prácticas limitadas por la posición de partida en el contexto histórico (Cachón, 1989; Cruselles, 1990).

Por tanto, la propiedad de bienes se fundamenta siempre en un conjunto de reglas abstractas que determinan el acceso, el control, el uso, la transferencia y la transmisión de cualquier realidad social que pueda ser objeto de disputa. El memorial de Fretero expresa cómo las estrategias sociales de los jueces y del tutor coincidían con el mundo familiar de origen de los menores. Catalina es la única superviviente de la tutela ya promovida a su nuevo ámbito de vida conyugal que percibirá el patrimonio restante del balance final del cabreve, gracias más al rédito censal del numerario que al cultivo de la viña, y lo hará 
junto a su esposo, con quien quizás comparta otro régimen de germanía. Así, pues, la sociedad no consiste en un sistema de niveles superpuestos sino más bien en un sistema de relaciones de cooperación entre las personas, de relaciones jerarquizadas según la naturaleza de las funciones que determinan cada una de las actividades humanas en el quehacer de la reproducción social. Y es la combinación de diversas condiciones materiales de vida la que permite a todos producir y reproducir los medios de su existencia. En esa labor, la familia en el Segorbe del siglo XV también deviene un auténtico marco de los procesos de supervivencia, ya que no sólo resulta el contexto más habitual de la reproducción de las propias personas en sí mismas (la reproducción biológica), sino que además contribuye a ordenar socialmente la vida más allá del nacimiento mediante reglas de matrimonio, filiación y tutela. De manera esencial, para que una actividad social como la familia desempeñe un papel tan importante en el funcionamiento y en la evolución de una sociedad, esto es, en el pensamiento y en la acción de las personas y de los grupos que componen dicha sociedad, no basta con que asuma muchas funciones, es imprescindible que asuma directamente, además de su finalidad y de sus funciones explícitas, la función de relaciones de producción (Navarro, 1992 y 1993).

\section{Edición del manuscrito}

1432, febrero, 25 - 1440, mayo, 3. Segorbe.

Cabreve de la tutela de los hijos de Pedro Martínez, difunto tejedor vecino de Segorbe.

- Archivo Histórico Municipal de Segorbe, Documentación Ajena, Serie Varia, $\mathrm{n}^{\circ} 256.78$ hojas de papel, $225 \mathrm{x} 115 \mathrm{~mm}$. Catalán y castellano.

- La primera transcripción de este manuscrito fue publicada en una revista local hace más de veinte años por los mismos autores de este artículo (Aparici y Navarro, 1997). En esta nueva edición se ha revisado dicha transcripción numerando los registros para disponer de unos índices de personas y lugares más exactos, al igual que se ha ampliado el análisis con diversas noticias inéditas sobre sus principales protagonistas que entonces desconociamos. Se espera así obtener una divulgación científica mayor para este interesante manuscrito a través de una revista académica de impacto con formato digital como es Aragón en la Edad Media. 
Jhesús

[1] Libre memorial, capbreu et, o, repertori de mi Johan Fretero, texidor vehí de Sogorb, tudor e curador testamentari que so de les persones e béns de Berthomico, Caterineta, Teresa e Isabeleta, fills e hereus d·en Pero Martínez, texedor quondam vehí de la dita ciutat de Sogorb, començat en 1.any Mil CCCC XXXII.

//ff. 1v-3v, en blanco//

Jhesús

[2] Primerament, dilluns a XXV de febrer, any Mil CCCC XXXII, yo ensemps ab en Dominguo el Toro, texidor vehí de la ciutat ${ }^{6}$ de Sogorb ${ }^{7}$ marmessor e execudor del testament del dit quondam en Pere Martínez, fiu inventari de tots los béns e drets qui eren comuns entre los dits pubils de una pat, e la mare dels dits pubils de la part altra, ab contracte ${ }^{8}$ reebut per Ramon del Ort, notari, sots lo dit kalendari, lo qual ne tinch en sa pública forma.

[3] Ítem, en aprés a [blanco] del mes de [blanco] del dit any Mil CCCC XXXII, ${ }^{9}$ los honrats en Martí d·Alloça e en Gil de la Cerda, vehïns de la dita ciutat, jutges asignats a partir e dividir los béns entre lo mi dit tudor de una part, e la mare dels dits pubils de la part altra, feren relació en poder del honorable justícia de $1 a^{10}$ ciutat, de la partició que feyta habien dels dits béns, seguons en aquella se pot occularment veure, de la qual relació ne tinch un trellat verbo ad verbum.

//f. 4v// [4] Ítem, en aprés a tres dies del mes de abril, any damunt dit Mil CCCC XXXII, fiu almoneda de certa part dels béns mobles dels dits pubils ${ }^{11}$ ab acte públich reebut per Ramon del Ort, notari, sots lo kalendari lo qual acte tinch en sa pública forma.

[5] Ítem, la major part dels béns mobles, los quals guardant-los se poden guardar e per procés de temps perir no poden ${ }^{12}$ precedent auctoritat e decret del honrat en Johan de Moros, justícia de la dita ciutat, foren per mi comanats a la dona na Catalina Guómez, mare dels dits pubils, seguons conste per contracte de comanda reebut per Ramon del Ort, notari, a tres de abril, any Mil CCCC XXXII, lo qual contracte yo tinch en sa pública forma.

[6] Ítem, a quatre de abril, any damunt dit Mil CCCC XXXII, ab acte públich reebut per lo discret en Bernat Rosselló, notari, e continuat en lo libre de 
assignacions sots lo dit kalendari, e procedent //f. 5// subastació legíttima feta per Johan Mançana, nunci de la cort de manament del honrat en Johan de Moros, justícia de la dita ciutat per XXX dies e molt més, atrentí la vinya dels pubils situada a Navajes, orta de Sogorb, confrontada ab vinya de Paricio Cerveró, prevere, ab vinya de Berthomeu Rosselló, e ab lo Camí Real, a temps de tres anys primer svenidors, e de la present jornada en avant continuament comptadors, a·n Anthoni Aragonés, major de dies, vehí de Sogorb, com a més preu dant per preu de XXXXVIIII sous cascun any, paguadors cascun any la mitat al mig any, e l·altra meytat en la fi del any, segons en lo dit acte és contengut.

[7] Ítem, la fanequada de terra dels dits pubils situada en Utriellas, jàtsia subastada no s.i troba atrentador, per quemquinque de necessitat donar-la a miges tansolament a un splet de dacça proper vinent. Et axí fou enseguit per obra.

[8] Ítem, a XXIII de abril del dit any Mil CCCC XXXII, en viguor de una requesta per mi feyta ordenar, honorable en Johan de Moros, justícia, tachà a Berthomico, pubil de etat de set a VIII mesos, per temps de un any per alletar-lo, XII sous per ${ }^{13}$ cascun mes, e a Isabeleta de provisió de menjar e beure, vestir e calçar, quatre diners cascun dia per temps de hun any, seguons en la dita requesta se conté.

//f. 5v// [9] Ítem, en aprés a XXV del mes de octubre, any damunt dit M CCCC XXXII, procedent legítima subastació feta per Johan Mançana, nunci e públich corredor, de manament del honorable en Johan de Moros, justícia, atrentí la fanequada de terra dels dits pubils situada en Utriellas, confrontada ab peça d·en Johan de Vilanova, ab peça d·en Johan de Noguera, e ab l·altra fanequada de na Caterina Guómez, mare dels dits pubils ${ }^{14}$, a·n Ximeno Descó, laurador veí de Sogorb, com a més de preu dant a temps de tres anys primer svinents e continuus, e per preu de XVII sous cascun any, paguadors ${ }^{15}$ ço és, la mitat al mig any e l·altra mitat al cap del any, seguons que del dit trent se mostre per un acte reebut per lo discret en Bernat Rosselló, notari, e continuat en lo libre de assignacions de la cort del dit honorable justícia sots lo dit kalendari.

//f. 6// [10] Trellat de la partició dels béns qui eren comuns entre los fills e hereus d·en Pere Martínez, texedor quondam de una part, e na Caterina Gómez, muller del dit en Pere Martínez et mare dels dits pubils, de la part altra.

//f. 6v// [11] Pagua al notari de la present còpia e trellat, III sous.

//f. 7// [12] Devant la presència de vos, molt honorable en Johan de Moros, justícia de la ciutat de Sogorb, personalment constituhits en Martí d·Alloça et en Gil de

13 Tachado: per cascun any.

14 Tachado: a camí.

15 Sobre línea: cascun any. 
la Cerda, vehïns de la dita ciutat, partidors et divisors per la vestra cort asignats a la partició fahedora entre en Johan Fretero, texidor, vehí de la dita ciutat, axí com a tudor e curador de les persones e béns de Berthomeu, Catalineta, Teresa e Ysabeleta, fills e hereus d·en Pere Martínez, texidor vehí de la damunt dita ciutat, defunt, de una part. E na Catalina Gómez, muller del dit Pere Martínez, et mare dels dits pubils de la part altra, dels béns e drets que quod comuns entre los dits conjuges en viguor de la fraternitat e jermanya entre aquells feta e causada en temps de contractament de son matrimoni. Segons que del poder a nosaltres atribuhit a fer la dita partició consta per actes de la vostra cort e per //f. 7v// comissió special a nos vera que·m feta. En axí, que en virtut de aquella, nós dits partidors, havien feta partició e divisió de tots los béns et drets que havem atrobat ésser comuns entre les dites parts, axí mobles com sehents, la part e mitat dels quals pertanyents als dits pubils entreguament és ací scrita et anotada, et encara la part pertanyent a la dita llur mare dels béns sehents per evitar frau com la sua part dels béns movents no haje volgut ací ésser continuada per tolre despeses, los quals dits béns axí partits pertanyents a les parts sobredites són los que, per orde, se seguexen. Primerament, pervingueren a la part dels dits pubils dels béns mobles:

[13] Ítem, un ordidor de fust.

[14] Ítem, un torn de fer canyelles.

[15] Ítem, ${ }^{16}$ unes devanadores ab son peu.

[16] Ítem, mig sclaví vell.

[17] Ítem, un cresol de ferre.

[18] Ítem, un banquet de fust.

[19] Ítem, una flaçada burella migada.

[20] Ítem, un maneres ab lo foure negre, lo pom redó.

[21] Ítem, un broquer.

[22] Ítem, una llança ab son ferre.

[23] Ítem, dos guarbelles d·espart.

[24] Ítem, una caxa vella de noguer, ab son pany e sa clau.

[25] Ítem, un cedaç.

[26] Ítem, un banch de fust.

[27] Ítem, una talequa rota.

[28] Ítem, una altra talequa blancha quasi nova.

//f. 8// [29] Ítem, altra talequa blancha oldana.

16 Tachado: $d$. 
[30] Ítem, un matalaf llistat de burell blanch e blau, ab la bitana vermella, plen de llana et les vores plenes d-estopa.

[31] Ítem, un traveser oldà listat de blanch et blau, ple de peçols de llana.

[32] Ítem, set lliures e quatre onzes de filaça d·estopa cuyta.

[33] Ítem, sis lliures e miga de filaça d·estopa crua.

[34] Ítem, una lliura e miga d·estam blanch.

[35] Ítem, un matalaf blanch e blau de cotonina, la bitana vermella, ple de llana.

[36] Ítem, quatre reconzadors pintats oldans plens d·estopa.

[37] Ítem, un coxí blanch oldà obrat, ab seda, ple de ploma.

[38] Ítem, un cofre vermell pintat a senyal de donzelles.

[39] Ítem, unes tovalles e un torquamans en un peçol, squaquades, de tres alnes.

[40] Ítem, altres tovalles de lli squaquades, de tres alnes.

[41] Ítem, altres tovalles de lli squaquades migades, de tres alnes.

[42] Ítem, altres tovalles de lli squaquades migades, de tres alnes.

[43] Ítem, altres tovalles d·estopa squaquades de dues alnes e tres pams.

[44] Ítem, altres tovalles d·estopa oldanes de dues alnes.

[45] Ítem, un tovalló nou d·estopa de tres alnes.

[46] Ítem, un parell de tovalletes de fil en pua de dues alnes e un pam cascuna.

[47] Ítem, dues tovalletes, I de lli e l-altra d·estopa, oldanes.

[48] Ítem, un llençol nou de tres teles de lli de vicar.

[49] Ítem, altre llençol de lli de tres teles ja usat.

[50] Ítem, altre llençol de lli de dues teles e miga ab randes.

[51] Ítem, altre llençol d·estopa nou.

[52] Ítem, altre llençol d·estopa quasi vell.

//f. 8v// [53] Ítem, una pastera de fust.

[54] Ítem, un traveser oldà llistat de blanch e blau ple de llana.

[55] Ítem, un coxinet blanch chich.

[56] Ítem, un post on estave la plegua.

[57] Ítem, un parell de pintes per a pentinar llana.

[58] Ítem, una pollera de canyes.

[59] Ítem, un tallador de fust.

[60] Ítem, una llegoneta d·entrecavar.

[61] Ítem, un morter de terra ab sa mà.

[62] Ítem, una rahedora de ferre. 
[63] Ítem, uns ferros de cuynar.

[64] Ítem, un librell de terra.

[65] Ítem, un ast de ferre.

[66] Ítem, una caldera de aram que cap un cànter.

[67] Ítem, un cabaç d·espart.

[68] Ítem, una taça d-argent que peça sis onzes.

[69] Ítem, més considerat que una cuba sens lo vi, que cap cent e sis cànters pochs més o menys, e una cubeta maresa, e onze jarres, les tres de $X$ cànters, et les set de quatren, et la una de dos cànters, et hun poal e dos perolls de portadores, ${ }^{17}$ los quals vaxells foren atrobats en lo celler, no's han poscut bonament sortiar ne partir, per ço aquells dits vaxells de fust e de terra havem stimats en Dèus et en nostres consciències en aquesta forma, //f. 9// ço és, la cuba sens lo vi en cent sous, la cubeta maresa en onze sous, les jarres e lo poal en vint-e-set sous, sis diners, et les portadores en VIII sous.

[70] En axí que la dita na Caterina Gómez ha pres en si los dits vaxells en preu de cent quaranta-sis sous, sis diners, dels quals pervendrien als dits pubils setanta-tres ${ }^{18}$ sous, tres diners.

[71] Ítem, encara deu tornar la dita Caterina Gómez als dits pubils per més valença de teler ab los arreus ${ }^{19}$ qui fou sortiat ab la taça d-argent qui pervench als dits pubils, cinch sous, sis diners. En axí que sumam ço que deu tornar la dita mare als pubils, setanta-huyt sous, nou diners, dels quals s-an a deduhir per rahó de les robes e vestidures qui foren venudes per los marmessors del últim testament del dit quondam Pere Martínez, per a complir les pies causes per aquell jaquides et la sua funeralla, les quals se veneren per preu de trenta-set sous, los quals pervendrien a la dita mare. En axí que deduhits dels dits setant-huyt sous, nou diners, que deuen cobrar los pubils de la mare los dits trenta-set sous que deu cobrar la mare dels pubils, resta purament per egualament de compte que deu tonrar la dita Caterina Gómez per als dits pubils, quaranta-hun sous, nou diners.

(Sitis)

[72] Dels béns sitis pervingueren a la part dels dits pubils los que-s segueixen.

[73] Primerament, una vinya situada en la partida apellada //f. 9v// de Navajes, orta de la dita ciutat de Sogorb, confrontada ab vinya de Paricio Cerveró, prevere, et ab vinya de Berthomeu Rosselló, et ab lo Camí Real, la qual és sots directa senyoria del honorable n’Eximeno Cuqualó, ciutadà de la dita

17 Tachado: $e$.

18 Tachado: se.

19 Tachado: lo. 
ciutat de Sogorb, et fa a aquell luisme et fadigua, et vint-et-hun sous de cens cascun any a cert benefici de la Seu de la dita ciutat en certs terminis paguadors, en preu o stimació de cent sous ab lo dit càrrech.

[74] Ítem, la meytat de aquelles dues fanequades de terra blancha, franques e quities, situades en la partida apellada Utriellas, orta de la dita ciutat, confrontades ab altra meytat qui ha pervengut a la dita Caterina Gómez, ab peça de Johan de Vilanova et ab peça de Johan de Noguera.

[75] Los béns sitis davall scrits pervengueren a la part de la dita na Caterina Gómez, muller del dit Pere Martínez, defunt, et mare dels dits pubils, com la sua part dels mobles, segons dit és, per tolre despeses no permeté fossen scrits ${ }^{20}$ et són los dits béns sitis aquestes ${ }^{21}$ següents.

[76] Primerament, una peça herma, francha e quita, situada en la partida del Campo, orta et terme de la dessús dita ciutat, que és cinch fanequades, confrontada ab vinya de hereus d·en Johan de Riglos, ab vinya de hereus d·en Johan Sánchez de Uncastiello, et ab vinya de Paricio Cutanda, en preu o stimació de cent sous.

[77] Ítem, la meytat de aquelles dues fanequades de terra blanqua, franches e quities, situades en la partida apellada //f. 10// de Utriellas, orta de la ciutat dessús dita, confrontada ab l-altra meytat qui ha pervengut als dits pubils, ab peça de Johan de Noguera, et ab lo camí que va a Lagunas, céquia en mig, en axí emperò que la part de la dita Caterina Gómez deu donar céquia et camí a $1 \cdot$ altra part e meytat dels dits pubils.

[78] Ítem, més havem considerat que los dits béns comuns són obliguats en XXXIII sous IIII diners moneda reals de València, censals, rendals e annuals ab benefici en la Seu de Sogorb per en Bernat López Cabrit quondam instituhit cascun any en certs terminis paguadors segons que en lo contracte de censal és més llargament contengut, los quals són ab carta de gràcia e foren originalment carregats per preu de CCCC sous, los quals CCCC sous foren preu principal de una vinya entre los dits conjuges comuna, situada en la partida de Lagunas, orta e terme de la dita ciutat segons que davall confrontada, la qual vinya lo dit quondam Pere Martínez, pochs dies eren passats, del últim testament del dit Bernat Lóppez et, per ço com no la pogué paguar del preu de aquella, carreguà lo dit censal a rahó de VIII sous IIII diners per centenar, e actenent que la dita vinya no pot ésser bonament partida sens gran deterioració de aquella, e considerat encara que fou car comprada, per ço de voler de la dita Caterina Gómez, et aquella ha pres et acceptat en si la dita vinya, la qual és confrontada ab peça d·en Jacme 
Gerart notari, ab vinya de Domingo Pérez texedor, e ab //f. 10v// senda, ab lo càrrech emperò dels dits XXXIII sous IIII diners censals, en axí que la dita Caterina Gómez guarde et sia tenguda guardar de dan et dampnatge als béns dels dits pubils, en axí que per rahó del dit censal et per la obligació general e special algun dampnatge als dits pubils ne a béns seus, no·ls pusca venir, ans sie imputat a la dita Caterina Gómez et a sos béns, en axí encara que aquella sia tenguda de continent o tota altra hora que $n$ serà requesta de fer e fermar carta de guardar de dan als dits pubils ab idonees caucions, et fermament roborada a discreció de bons notaris, et a tot profit dels dits pubils.

[79] Cum etiam, considerat que los dits cónjuges són obliguats en dar e paguar a Johan Ferrández, forner vehí de Sogorb, cent setant sous, los quals aquell los li comanà en comptants segons que la dita comanda et deute a nosaltres legittimament ha constat per testimonis dignes de fe, per tant havem jaquit lo vi qui és en la dessús mencionada cuba per partir, en axí que quant aquell dit vi se vendrà sia venut per lo dit tudor e curador et per la dita Caterina Gómez in simul, et del preu que d·aque·n exirà, sien paguats al dit Johan Ferrández los dits cent setant sous. Et si del preu del dit vi alcuna cosa sobrarà, allò sia partit entre lo dit tudor et ${ }^{22}$ curador et la dita Catalina //f. 11// Gómez equiis porcionibus. E si per ventura lo preu del dit vi no bastave a paguar los dits cent setant sous, en tal com abduy les dites parts sien tengudes de fer compliment per eguals parts.

[80] Ultimadament, attès que lo fruyt qui a present és en les dites dues fanequades de terra de Utriellas jàtsie la peça sie partida no·s pot bonament partir sens frau et evident ${ }^{23}$ enguan de la una de les parts, per ço hauda la dita consideració ho havem partit lo dit fruyt qui és ordi, ans aquell dehim deure ésser cullit de tot una, et ço que Dèu hi darà del dit fruyt, sie entre les dites parts per eguals parts compartit. Altres béns sitis ni movents sinó los damunts dits, nós en Martí d·Alloça et en Gil de la Cerda, partidors, no havem pogut atrobar dels quals hajam poguda fer partició per la qual rahó nos offerim e som prests fer et enseguir vostres justs manaments. E axí com a jutges partidors damunt dits a lo dit molt honorable justícia relació de totes e sengles coses designades et mencionades ésser axí enseguides et passades si, et segons que dessús és scrit et annotat.

//f. 11v a f. 15, en blanco//

//f. 15v// Die lune XXIIII ${ }^{\circ}$ augusti, anno XXXIII ${ }^{\circ}$

22 Tachado: la.

23 Tachado: peril. 
[81] Ítem, un llençol d·estopa oldà de dues teles e miga. ${ }^{24}$

[82] Ítem, altre llençol d·estopa nou de dues e miga.

$\mathrm{Vs}$.

[83] Ítem, un llençol de lli ab vandes de dues teles e miga, migat.

[84] Ítem, altre lençol de li de bicar, de tres teles quasi nou.

X s. VII.

[85] Ítem, un lençol de stopa de bicar de tres teles, nou.

[86] Ítem, unes tovalles de lli noves, squaquades, de tres alnes.

[87] Ítem, unes tovalles d·estopa squaquades noves, ab un torquamans.

[88] Ítem, unes tovalles de lli de tres alnes squaquades, migades.

[89] Ítem, unes tovalles d·estopa de dues alnes e miga squaquades.

[90] Ítem, dues tovalletes de lli migades ${ }^{25}$ de dues alnes cascuna.

[91] Ítem, un tovalló d·estopa nou de tres alnes.

[92] Ítem, dotze tovallons de li oldans, de dues alnes cascú.

[93] Ítem, unes tovalles d·estopa de dues alnes cordonades oldans.

[94] Ítem, un coxinet blanch chich, de llenç, oldà.

[95] Ítem, un coxinet blanch orbrat de seda ple de ploma.

[96] Ítem, quatre reconzadors pintats oldans, plens de stopa.

[97] Ítem, una flaçada bruxellada migada.

[98] Ítem, un matalàs blanch e blau de cotonina, la bitana bermella, ple de llana, quasi nou.

VI s.

XII s.

XVIII s.

VII s.

VI s.

V s.

III s.

IIII s.

II s. VI d.

II $\mathrm{s}$.

I s. VI d.

VI d.

I s.

IIII s. VIII

d.

XXVI s.

$(\ldots)$

[99] Ítem, un traveser nou llistat de blanch e blau, ple de palla.

[100] Ítem, un cofre vermell pintat ab senyal de donzelles.

(...)

XII s.

[101] Ítem, una taça de argent que pesa sis onzes, marquada de march de València, a rahó de XIII per onza.

LXXVIII s. Sumam de plana: CCXXXXVII s. VIII.

//f. 16 a f. $19 v$, en blanco// 
//f. 20// [102] Reebudas fechas por en Johan Fretero, tudor e currador de los fijos d en Pero Martínez, texidor, de los bienes a Catalinita e Teresuca puvillas como de las hotras tengan su part, del anyo mil quatrozientos trenta e seys, e son las siguientes:

[103] Primerament possà en reebuda que recibia de logero de huna cuba para de las de ditas puviles ell qual legó para su ben. ${ }^{26}$

[104] Primo, la rebuda del any XXXV són XIIII cànters.

XXVI s.

[105] Primerament possà en reebuda ell dit tudor que recibió de la binya de las dictas puvilas la qual possesió en Navajas és a saber, cinquanta cántaros de bino, ell qual bendió por menudo a diversos precios, es a saber a ocho e seys dineros ell cántaro, que suma trenta sueldos.

[106] Ítem, après possà en reebuda ell dit tudor, que recibió de $(\ldots)$ la binya de las $\mathrm{d}$.

//f. 20v// [107] Reebudas fechas por ell dicto tudor e currador de los bienes de las dichas puvillas en ell anyo mil CCCC XXXVII.

[108] Primerament possà en reebuda que recibió de bino de la binya de las dichas puvilas, cinquanta cánteros, ell qual bendió por menudo a dotze, que suma cinquanta sous.

[109] Ítem, en el anyo XXXVIII sallieron XVIII cántaros a XVI de precyo.

[110] Ítem, en el anyo XXXVIIII sallieron XVI cántaros, a XVI de precyo.

[111] Ítem, vint sous se deven meter en reebuda del guany dels diners.

[112] En 1·anyo XXXV costó de vendemar, acarrear,28 pisar, vendemar, loguero de cubo e de jarra:

[113] ço és de vendemar.29

XXIIII s.

XXIIII27 s.

XX s.

[114] acarrear.

[115] pisar tres carguas.

I s. II.

I s. VI. ...S. VI.

26 Margen izquierdo, añadido: vide para ponatur a Berthomeu Anthoni Aragonés, en propia. Esta última palabra está tachada.

27 Tachado: XXV s. IIII.

28 Añadido al margen izquierdo: acarrear.

29 Tachado: acarrear. 
[116] loguero de cubo con feguar.

III s. VI.

[117] reguar.

I s. VIII.

[118] scardar.

II s.

Vide pro ut, in cedula quod isto anno tutor fecit poderar vinya. ${ }^{30}$

//f. 21r// [121] Datas fechas por ell dito tudor de los bienes de las dictas puvilas en ell anyo $\mathrm{M}^{\circ} \mathrm{CCCC}^{\circ} \mathrm{XXX}^{\circ} \mathrm{VII}^{\circ}$, e son los deiús scritos:

[122] Primerament possà en data que dio e pagó a los peyones de podar la binya de las ditas puvilas e cuire bino e pitança, es a saber seys sous e medio.

[123] Ítem, après possà en data que dié e pagé de escardar la dita binya dos sous tres diners de bino e pitança.

VI s. V d.

II s. III d.

[124] Ítem, así·s possà en data que dio e pagó a hun ombre de regar la dicta vinya, dos sous.

[125] Ítem, après possà en data que dio e pagó de loguero de hun cubo para la bendema, cinquo sous, e ocho dineros de fregar e agua.

[126] Ítem, après possà en data que pagó a dos31 hombres de bendemar a quinze dineros, de vino e pitança quatro dineros, que suma dos sueldos diez dineros.

[127] Ítem, de pisar la dicta bendema nous dineros, e de logera de dos pares de portaderas, hun sueldo.

//f. 21v// [128] Ítem, possà en data que dio e pagó de logerio de una cuba que logó para ell bino de las dictas pubilas, cinquo sueldos e ocho dineros de cuir, fregar e agua, e hun sou de saquar ell bino.

\section{Anyo M CCCC XXXVIIII ${ }^{\circ}$}

[129] Podar et alia istius anni vide albaranum Andree de Cutanda, sub certo signo. ${ }^{33}$

[130] Vide en l-any XXXVIIII in alia cedula certo signo. ${ }^{34}$

//f. 22//

Jhesús

30 Al margen izquierdo, dibujo de una mano con dedo índice.

31 Tachado: hun.

32 Este ítem se repite más tarde (\$259). En él sí se indica correctamente la cantidad: VI s. VIII d.

33 Al margen derecho, dibujo de una estrella.

34 Al margen derecho, dibujo de un lazo en forma de 8. 
[131] Reebudes fetes per mi Johan Fretero, texidor, tudor e curador qui so de les persones e béns dels fills e hereus d·en Pere Martínez, texidor quondam, vehí de la ciutat de Sogorb, les quals reebudes són pro ut secuntur:

[132] Reebudes almoneda. Primerament, pos en reebuda de una almoneda que fiu a tres de abril, any mil CCCC XXXII seguons que en lo acte $d \cdot a q u e \cdot n$ fet se mostra, e reebut per Ramon del Ort, notari, sots lo dit kalendari.

LXXXVII s. VIIII

[133] Vi. Ítem, del vi que romàs en la cuba per partir lo preu del qual romangué comú per a paguar cent setanta sous que eren deguts a·n Johan Ferrández, forner, seguons forma de la partició de aquest vi no faç entrada ne exida per ço que la dona na $\mathrm{Ca}-$ terina Gómez a dan seu se passà al dit be e pres càrrech de paguar los dits CLXX sous, la qual hac de fer de sa bossa com no li bastàs lo preu que ixqué del dit vin.

Sumam de plana LXXXVII s. VIIII.

//f. 22v// [134] Ítem, mes pos en reebuda de la meytat del ordi que ixqué de la peça e fou quinze 35 barcelles, de les quals deduhida la una barcella36 e la palla que doní per la meytat de les despeses del seguar e trillar, restaren-me purament XIIII37 barcelles sens palla, les quals vení a diverses persones a rahó de III sous IIII diners per fanegua, que puien in universo.

[135] Ítem, mes pos en reebuda per mig cafiz de dacça que reebí a part dels pubils de la peça de aquells situada en Utriellas, la qual attés que no troba atrentador dono a miges tansolament a aquest splet, nous sous, e vení la dicta dacça38 a XXI de octubre any mil CCCC XXXII.

XXIII s. IIII.

Sumam de plana: XXXII s. IIII d.

35 Tachado: setze.

36 Sobre línea: barcella.

37 Tachado: $X V$.

38 Sobre línea: dicta dacça. 
[136] Ítem, pos en reebuda les quals reebí de n·Anthoni Aragonés, laurador vehí de Sogorb, per rahó de la primera pagua de la primera anyada del preu del //f. 23// atrentament de la vinya en Navajes dels dits pubils, que li atrentí a temps de tres anys, e per preu de XXXXVIIII sous cascun any, ço és, vint e quatre sous, sis diners.

[137] Ítem, pos en reebuda de la dona na Caterina Gómez per una taula que li vení en que staba la plega.

XXIIII s. VI.

I s.

[138] Ítem, pos en reebuda XXIIII sous VI diners los quals reebí de $\mathrm{n} \cdot$ Anthoni Araguonés per rahó de la seguona pagua de la primera anyada del preu del atrentament de la vinya dels pubils situada en Navajas, que li atrentí a temps de tres anys per preu de XXXXVIIII sous cascun any.

Sumam: L s.

[139] Ítem, pos en reebuda de una almoneda que per manament dels jutges partidors fiu a $\mathrm{X}$ de setembre any mil CCCC XXXIII ab acte reebut per Ramon del Ort, notari, sots lo dit kalendari, la qual almoneda puja in universo cinquanLVI s. IIII d. ta-sis sous, quatre diners.

Sumam de plana: CVI s. IIII d.

//f. 23v// [140] Ítem, pos en reebuda de altra almoneda que per manament dels dits jutges partidors fiu pro ut lo dit notari e ab acte reebut per aquell a XII de nohembre any mil CCCC XXXIII la qual puja in universo noranta-quatre sous, tres diners.

[141] Ítem, per manament dels jutges partidors per ço que pus fàcilment sapien los béns dels dits pubils en quina vàlua són, a fin que de aquells pervixqueren fer partició en fer los dits pubils, continue en lo present libre en reebuda jàtsia que a veritat no 1 s he encara39 reebuts, XXIIII sous VI diners de la pagua de quatre de octubre del any mil CCCC XXXIII del trent de la vinya dels dits pubils situada en Navajas, la qual té atrentada Anthoni Aragonés per LXXXXIIII s. III d. XXXXVIIII sous l-any. 
[142] Ítem, més continuem en reebuda per manament dels dits jutges partidors jàtsia que en veritat e rahonablement no·ls he reebuts com no sia benguda la pagua per la prorata del dit trent de la vinya40 deguda dels dessús dit quatren dia de octubre any XXXIII tro en lo primer dia de jener, any mil CCCC XXXIIII41 que seran tres mesos, XII sous III diners.

XII s. III.

Sumam de plana: CXXXI s.

//f. 24// [143] Ítem, per semblant pos en reebuda jàtsia encara no'ls haia reebuts deheset sous per lo trent de una anyada de la fanequada de terra dels dits pubils situada en Utriellas, la qual té atrentà Ximeno Descó, vehí de Sogorb a tres anys per preu de XVII sous l-any, e la qual dessús dita anyada és la primera del dit trent e complí a XXV de octubre any mil CCCC XXXIII.

[144] Ítem, axí mateix continue en reebuda de la prorata del propdit trent deguda del dit XXVen dia de octubre, any M CCCC XXXIII tro en lo primer dia de jener any CCCC XXXIIII, segons feren compte los dits jutges, de dos mesos e deu jorns, tres sous tres diners.

XVII s.

III s. III.

[145] Ítem, pos en reebuda del preu de la taça de argent dels dits pubils que pesa sis onçes, la qual vení a rahó de XIII sous la onza, que puje a número de setanta-huyt sous.

Sumam de plana: LXXXXVIII s. III d.

//f. 24v// [146] Sumam universal de totes les reebudes continuades en lo present libre, en tres cartes la present compresa, quatrezents cinquanta-cich sous huyt diners.

[147] Ítem, foren stimades la vinya dels pubils, situada en Navajas, en cent sous, e la fanequada de terra situada en Utriellas en do-hents sous, que són per tot tre-hents sous.

CCCCLV s. VIII.

[148] En axí que fahent acumulació de tots los béns dels pubils entre los diners e la vàlua de les heretats, pujen a número de set-zents cinquanta-cinch42 sous, huyt diners.

DCCLV s. VIII. 
//f. 25 a 30v en blanco//

//f. $31 / /$

Jeshús. Dates.

[149] Dates fetes per mi, Johan Fretero, texidor, vehí de la ciutat de Sogorb, tudor e curador qui so de les persones e béns dels fills e hereus d·en Pere Martínez, texedor quondam, vehí de la dita ciutat, les quals reebudes són pro ut secuntur:

[150] Primerament, pos en data que comprí lo present libre per $\mid$...s VI d. sis diners.

[151] Ítem, pos en data los quals doní a Johan Mançana, corredor, per lo seu lloguer de subastar, vendre e trantar los béns de la almoneda, dos sous, tres diners, seguons conste per albarà fet, scrit de mà de,43 quatre de abril, any mil CCCC XXXII.

[152] Ítem, pos en data al discret en Bernat Rosselló, notari, quatre sous sis diners, ço és per la mitat del salari de la requesta dels partidors e per la mitat del salari de la requesta dels partidors [sic] e per la mitat del salari de la44 relació et partició dels béns entre los dits pubils de una part, e la mare de aquells feta, et per una requesta de provisió del dits pubils de tot los dits IIII sous VI diners, seguons conste per albarà scrit de mà del dit en Bernat Rosselló, a XXIII de abril any mil CCCC XXXII.

I s. III d.

Sumam de plana: VII s. III d.

//f. 31v// [153] Ítem, pos en data a·n Johan Mançana, corredor, per còrrer e subastar lo trent de la vinya dels pubils, tres sous, et a·n Bernat Rosselló, scrivà de la cort, per lo salari de continuar lo trent, sis diners, que són per tot tres sous sis diners, seguons conste per albarà scrit de mà del dit en Bernat Rosselló, a V de maig any mil CCCC XXXII.

III s. VI.

[154] Ítem, pos en data a Ramon del Ort, notari, per lo testament del dit quondam en Pere Martínez, XI sous. Ítem, per hinventari dels béns, set sous. Ítem, per l-almoneda, tres sous, los quals li foren tachats per los tachadors seguons que en lo dors dels dits actes se mostra. Ítem més per rahó de $^{45}$ la meytat del salari al dit notari pertanyent 
de ordenar la requesta en viguor de la qual foren asignats los jutges comptadors e per entervenir en la partició e per ordenar la relació, quatre sous, que són per tot XXV sous seguons conste per albarà scrit de mà de Ramon del Ort, notari, a III de juny any mil CCCC XXXII.

XXV s.

Sumam de plana: XXVIII s. VI d.

//f. 32// [155] Ítem, pos en data a·n Jacme Pexó per la sisa de la almoneda que fiu dels béns dels dits pubils, hun sou segons conste per albarà scrit de la sua mà pròpria, a III de juny any mil CCCC XXXII.

[156] Ítem, pos en data a·n Pasqual de Coria com a col-lector dels censals del benefici del fill del honorable en Luís Vicent, al qual benefici la vinya dels dits pubils fa XXI sous de cens cascun any, la mitat a Nadal et l-altra meytat a sent Johan de juny, X sous VI, e los quals són de la solució de sent Johan del any XXXII segons conste per albarà scrit de mà del dit col·lector a XII de agost, any mil CCCC XXXII.

[157] Ítem, pos en data a la dona na Catalina Guómez, mare dels dits pubils per ço com alletà e nodreix a Berthomico et Isabeleta menors, pubils dessús dits, e en pagua e prorata de ço que li deig paguar, conste per albarà scrit de mà de Ramon del Ort, notari, a XXI de octubre any mil CCCC XXXII.46

[158] Ítem, paguí al notari del albarà com fiu còpies.

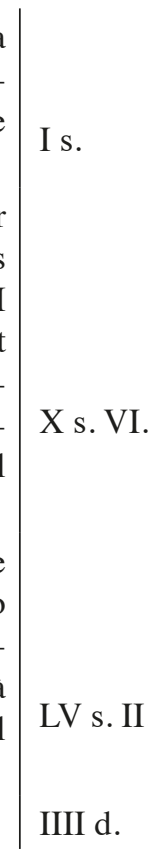

Sumam de plana: LXVII s.

//f. 32v// [159] Ítem, pos en data a la dita Caterina Guómez per a comprar una fanequa de forment e una lliura de cera a obs de portar47 1·anyal del dit en Pere Martínez per ço como los marmessors no·n han complit, VIII sous IIII diners, seguons consta per albarà fet de mà del damunt VIII s. IIII d. dit Ramon del Ort, notari, a XXI de octubre any mil CCCC XXXII.

46 Añadido al margen izquierdo: aquests LV sous II diners, e los IIII diners del albarà, no són mesos en compte de les dates fetes en la comunitat de los pubils, com solament sien ganàncies en pròpria necessitat dels menors, e per ço continuaré aquells en les dates que faç als dits menors.

47 Tachado: portal. 
[160] Ítem, pos en data al discret en Bernat Rosselló notari scrivà de la cort, e per continuar en lo libre de asignacions lo trentament per mi fet de la fanequada de terra dels dits pubils, sis diners, et a Johan Mançana nunci e públich corredor, per còrrer, subastar e trantar lo dit trent, vint diners, que són per tot dos sous dos diners, seguons consta per albarà scrit de mà del dit en Bernat Rosselló, a XXV de octubre any mil CCCC XXXII.

//f. 33// [161] Ítem, pos en data a Ramon del Ort, notari, cinch sous sis diners, ço és, los tres sous per rahó de un trellat que feu de la partició e relació de jutges feta entre mi de una part, en lo dit nom, e la mare dels dits pubils de la part altra. E los dos sous sis diners per rahó de continuar lo present capbreu, ço és ${ }^{48}$ reebudes e dates seguons conste per albarà scrit de sa pròpria mà, $\mathrm{a} \mathrm{V}$ de febrer any mil CCCC XXXIII.

[162] Ítem, pos en data a Pascual de Coria com a col·lector del benefici del qual és beneficiat lo fill del honrat en Luys Vicent, deu sous sis diners, los quals són de la pagua de Nadal del any XXXIII del cens que fa la vinya de Navajes al dit benefici, seguons conste per albarà scrit de mà de Pere del Ort, Pascual de Coria, a XV de febrer any mil CCCC XXXIII.

II s. II.

V s. VI.

X s. VI.

Sumam de plana: XVI s.

//f. 33v// [163] Ítem, pos en data a Jacme Dassio, clergue beneficiat del benefici per 1-onorable en Monton, quondam, instituhit, al qual la vinya de Navajas dels dits pubils fa XXI sous de cens cascun any a Nadal e a sent X s. VI. Johan mediatum, X sous VI diners, de la pagua de sent Johan propassada del any M CCCC XXXIII, seguons consta per albarà scrit de sa pròpria mà, a XXI de agost any M CCCC XXXIII

[164] Ítem, pos en data al honorable en Miquel Just, pebostre de la confraria de sent pare Blay, de la dita ciutat de la qual lo dit quondam en Pere Martínez, pare dels dits 
pubils, ere confrare mentres vevie, cinch sous per rahó de la sua fi, com los marmessors no u haguessen paguat, seguons consta per albarà scrit de sa pròpria mà a XVIII de febrer any M CCCC XXXIII.

Sumam de plana: XV s. VI.

//f. 34// [165] Ítem, pos en data que paguí al honorable n·Eximeno Cuqualó, ciutadà de Sogorb, senyor directe de la vinya dels pubils situada en Navajas, cinch sous per lo mig loisme a ell pertanyent de la partició de la vinya feta ensemps ab los altres béns entre los dits pubils e la mare, seguons consta per albarà scrit de sa pròpria mà, a XII de nohembre any M CCCC XXXIII.

[166] Ítem, pos en data al discret en Bernat Rosselló notari scrivà de la cort, nou diners per la provisió enantament qui feu e scriví de la tachació que feu lo justícia a instància mia pròpria, per la requesta que fiu e posí a XI de setembre any mil CCCC XXXIII que fos tachada ...s. VIIII. provisió a Berthomeu e Isabeleta menors pubils segons que la dita solució per scriptura de mà del dit en Bernat Rosselló en la dita requesta scrita. ${ }^{49}$

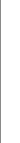

Sumam de plana: V s. VIIII.

//f. 34v// [167] Ítem, pos en data a Johan de Belmunt, corredor, XII diners per rahó de una almoneda que aquell de manament meu feu de béns dels dits pubils a $X$ de setembre any M CCCC XXXIII, segons consta per albarà scrit de mà de Ramon del Ort, notari, a XII de setembre any M CCCC XXXIII.

[168] Ítem, pos en data a·n Johan Ruvio, vehí de Sogorbe, nou diners per rahó que aquell de manament meu acarreià la roba dels pubils de casa a la plaça per fer almoneda e tornà la major partida com no`s vené en la primera almoneda, segons conste per albarà scrit de mà de $\mathrm{n} \cdot$ Anthoni Beyites.

49 Al margen izquierdo, añadido: de aquesta data són a deduhir no és mesa en compte de les dates fetes per la comunitat de tots los pubils com sie convertida en pròpria necessitat dels menors e per ço deu ésser mesa en lo compte dels dits menors. En este parágrafo está tachado: són a deduhir. 
[169] Ítem, pos en data a Ramon del Ort, notari, quatre sous per les rahons següents, primo I sou per ordenar una scriptura de requesta de50 partició entre los dits pubils. Ítem, per entervenir en la almoneda dessús dita e liurar-ne aquella en sa pública forma, II sous. E hun diner51 per ordenar una requesta de provisió segons larguament consta per albarà scrit de mà del dit notari, a XV de setembre any M CCCC XXXIII.52

IIII s.

Sumam de plana: V s. VIIII.

//f. 35// [170] Ítem, pos en data al honorable en Johan Aragonés, perayre col·lector del morabatí, VII sous, los quals feren paguar als dits pubils segons larguament consta per albarà scrit de mà del dit en Johan Aragonés, a XX de setembre any M CCCC XXXIII.

[171] Ítem, pos en data a n·Anthoni Aragonés, menor, col·lector de la peyta e de les fanequades, ço és a una part IIII sous VI diners de la peyta dels pubils, e VIII diners per la fanequada dels pubils per a obs de la reparació de la céquia de las Cabeçadas del Campo, que són per tot V sous II diners, segons consta per albarà scrit de mà de Ramon del Ort, notari, a IIII de dehembre any M CCCC XXXIIII.

VII s.

Sumam de plana: XIIII s. VIII.

//f. 35v// [172] Ítem, pos en data al discret en Jacme Dassio clregue beneficiat del benefici al qual la vinya dels pubils fa XXI sous de cens, deu sous sis diners per la pagua de Nadal del any mil CCCC XXXIIII segons conste per albarà.

[173] Ítem, pos en data al honorable en Pere Dassio e a sos companyons sisers, per la sisa de les dues almonedes últimament fetes que pujaren a número de cent cinquanta sous set diners, a rahó de tres diners per lliura, a la part dels pubils hun sou deu diners segons consta per albarà.

X s. VI d.

I s. X.

50 Tachado: provisió.

51 Error del escribano: diner en lugar de sou.

52 Al margen izquierdo, añadido: de aquesta data ne són deduhits e levats dotze diners los quals paguí per la requesta de provisió com aquells sien considerats en pròpria necessitat dels dos pubils menors, ço és Berthomico e Isabeleta, e per ço aquells deuen ésser continuats en les dates fetes als dits menors. 
[174] Ítem, pos en data al discret en Bernat Rosselló notari scrivà de la cort per la tachació de la provisió dels dos pubils menors de la segona amerada, dotze diners segons conta per albarà. Aquesta data és dalt continuada e solament és de nou diners, e per ço és ací cancellada.53

Sumam de plana: XII s. IIII.

//f. 36// [175] Ítem pos en data a Ramon del Ort, notari, dos sous per rahó que aquell entervingué54 en la última almoneda feta dels béns dels pubils e liurar-me aquella en sa pública forma segons consta per albarà scrit de sa pròpria mà $\mathrm{a}$.

[176] Ítem, pos en data al dit Ramon del Ort, notari, per rahó que aquell entervingué ab en Gil de la Cerda, e en Domingo el Toro, partidors en la partició per aquells feta en fer los dits pubils, e per ordenar la dita relació, quatre sous, segons consta per albarà scrit de sa pròpria mà a.

[177] Ítem, pos en data al discret en Bernat Rosselló, notari scrivà de la cort, per continuar la requesta de la partició dels béns entre los dits pubils per continuar55 la propdita relació dels béns dels dits jutges partidors, dos sous sis diners, segons consta per albarà.

IIs. VI.

IIII s.

Sumam de plana: VIIIs. VI.

//f. 36v// [178] Suma universal de totes les dates fetes per lo56 de dit en Johan Fretero, tudor e curador per los dits pubils, cent noranta-hun sous nou diners.

[179] Dels quals, deduhits e llevats cinquant-huyt sous tres diners que són stats paguats en pròpria necessitat de Berthomico e Isabeleta menors, segons se mostra en les postilles del present compte. Restaria purament ésser stat despés per tota la comunitat dels dits pubils cent trenta ${ }^{57}$

CLXXXXI s.

VIIII d.

CXXXIII s. VI.

53 El ítem está tachado, pero al margen izquierdo se añade: aquests dotze diners no entren en lo compte de les dates fetes en la comunitat dels pubils com aquells sien despeses en causa pròpria de Berthomico e Isabeleta menors.

54 Tachado: e feu una almoneda.

55 Tachado: relació dels propdits jutges partidors.

56 Tachado: tudor.

57 Tachado: tres. 
sous sis diners com los sobredits LVIII sous III diners deuen ésser donats en compte ${ }^{58}$ als dessús dits dos pubils menors de ço que li·s pervendrà en virtut de la partició feta entre tots los quatre pubils.

CXXXIII s. VI.

//f. 37// [180] Los quals dits cent trenta-tres sous sis diners, deduhits e llevats dels set-zents cinquanta-cinch sous huyt diners que pujen tots los béns dels pubils, resta purament et per a finament de compte los béns dels dits pubils in universo ésser en vàlua de sis-cents vint-dos sous, dos diners, los quals fetes quatre eguals parts ve a cascuna part, ço és, a cascun pubil, cent cinquanta-cinch sous, sis diners, mella.

[181] Los quals dits CLV sous VI diners, mealla, deven ésser paguats als dits pubils en la forma en la relació dels jutges partidors, ço és, d·en Gil de la Cerda e d·en Domingo el Toro mencionada.

DCXXII s. II.

CLV s. VI d.

$/ / f .37 \mathrm{v}$, en blanco//

//f. 38//

Jhesús

Esta relació de mandato dictorum iudicum fuit expedita in mense januarii anno $M^{o}$ $\mathrm{CCCC}^{o} \mathrm{XX} \mathrm{X}^{\circ}$ IIII $^{\circ}$.

[182] Devant la presència de vos molt honorable en Ramon del Ort, jutje de la ciutat de Sogorb, personalment constituhis en Gil de la Cerda, laurador, et en Domingo el Toro, texidor, vehïns de la dita ciutat, partidors e divisors per la vostra cort asignats en la partició fahedora ${ }^{59}$ de tots los béns que són comuns per judici és entre ${ }^{60}$ Berthomico, Catalineta, Theresa e Isabeleta, fills et hereus d·en Pere Martínez, texedor ${ }^{61}$ quondam, segons que del poder a nosaltres atribuhit consta per actes de la vostra cort et per comissió special a nos d·aque·ren feta, la qual partició és stada requesta justament per en Johan Fretero, texidor vehí de la dessús dita ciutat, tudor e curador testamentari dels dits pubils, per ço que cascú de aquells conegua sa part a fi que lo dit tudor e curador sàpia de què ha de respondre et alimentar a cascú per ço que los uns no gasten los béns dels altres, per la poqua vàlua en que són los béns de la dita herència.

58 Tachado: conste.

59 Tachado: entre.

60 Sobre línea está la frase: de tots los béns que són comuns per judici, és entre.

61 Tachado: E açò. 
[183] En axí, que en virtut de la dita ${ }^{62}$ comissió, nosaltres dits partidors havem feta partició //f. 38v// e divisió de tots los béns ${ }^{63}$ que havem trobat ésser comuns entre los dits pubils, axí mobles com sehents en aquesta forma. E primerament havem vist ad occulum la partició feta entre los dits pubils e la dona na Caterina Gómez, mare de aquells, en virtut de la germania entre aquella e lo dit quondam en Pere Martínez, texedor, marit seu en lo temps de llur matrimoni feta e contractada.

[184] En aprés havem vist com per lo dit tudor e curador fou feta almoneda de certa part dels béns qui pervingueren als dits pubils en públich enquant e com certs altres béns ${ }^{64}$ entervenint auctoritat de nostra cort foren acomanats per lo dit tudor e curador a la dita na Caterina Gómez ab acte públich reebut per Ramon del Ort, notari, a tres de abril any M CCCC trenta-dos, ${ }^{65}$ los quals béns ${ }^{66}$ no obstant los rahonaments fets en lo dit contracte per elapsu temporis, reebrien gran deterioració e menys valença, per ço per aquest e altres sguarts molt justs ${ }^{67}$ manam al dit tudor e curador aquells ésser venuts en públich enquant per ço que ${ }^{68}$ preu de aquells pus fàcilment pugués ${ }^{69}$ ésser feta partició e lo qual dit tudor e curador per lo dit per nosaltres a ell fet manament ha venuts los dits béns segons que en dos actes de almoneda ${ }^{70}$ reebuts per lo dit Ramon del Ort, notari, la hu a X de setembre e l-altre a XII de nohembre del any M CCCC XXXIII pus larch appar.

[185] Cum etiam havem vist los comptes del dit en Johan Fretero, tudor e curador dessús dit, e les reebudes e dates a administració per aquell fetes per encerquar e scontar //f. 39// diligentment que tots los béns dels dits pubils ab íntegre vinguessen en la present partició. E havem trobat per veritat les reebudes fetes per lo dit tudor e curador de tres almonedes e dels trents e loguers de la vinya situada en Navajes, e de la fanequada de terra situada en Utriellas dels dits pubils deiús confrontades contant les prorates dels trents tro en lo primer dia del $^{71}$ present mes de jener del any M CCCC $\mathrm{XXXIIII}^{72}$ pujar in universo a número de quatre-cents cinquanta-cinch sous huyt diners.

62 Tachado: $a$ nos.

63 Tachado: e drets.

64 Tachado: entre.

65 Tachado: en la.

66 Tachado: per nosaltres són stats manats fer.

67 Tachado: havem.

68 Tachado: lo.

69 Tachado: són fes.

70 Sobre línea: de almoneda.

71 Sobre línea: primer dia del. Tachado: corrent mes.

72 Sobre línea: del any MCCCC XXXIIII. 
[186] Ítem, havem stimat la dita vinya dels dits pubils situada en Navajes, confrontada ab vinya de Paricio Cerveró, prevere, ab vinya de Berthomeu Rosselló e ab lo Camí Real, ab càrrech de XXI sous censals cascun any a un benefici en la $^{73}$ Seu de Sogorb ${ }^{74}$ instituhit en certs terminis paguadors e ab luisme e fadigua e tot altre plen dret imphiteotich censat segons fur de València en preu e stimació de cent sous.

[187] Ítem, per lo sguart deiús designat stimam la dita fanequada de terra situada en Utriellas confrontada ab l·altra fanequada de la dita na Caterina Gómez, ab peça de Johan de Vilanova e ab peça de Johan de Noguera, en preu e stimació de dohents sous.

[188] En axí que los béns que·s troben a present pertany als dits pubils,$^{75}$ in universo acomulats la vàlua e número de aquells pujen set-zents cinquantacinch sous huyt diners.

[189] En après havem vist e diligentment scrutat les dates per los dit //f. 39v// tudor e curador axí en censos, peyta, morabatí, salaris de notari ${ }^{76}$ corredors e altres diverses despeses ${ }^{77}$ fetes concernents comunal profit e interés de tots los dits quatre pubils segons per lo conte del dit tudor e curador a nosaltres mostrat, e per los albarans d·aque·n fets appar, les quals pujen a número de cent trenta-tres sous sis diners ${ }^{78}$ com lo dit tudor haie fetes altres dates pujants a número de cinquanta-huyt sous tres diners, los quals solament són stats convertits en pròpria e privada necessitat dels dits Bertholomico e Isabeleta menors, e per ço aquells no fiu a deduhir de la universal suma, ans per aprés feta la present pertició per lo dit tudor e curador deuen ésser donats en compte als dits menors de ço que per virtut de la present partició li·s pervendrà, los quals dessús dits cent trenta-tres sous sis ${ }^{79}$ diners en comuna necessitat destribuhits e despesos, deduhits e levats dels damunt mencionats set-zents cinquanta-cinch sous huyt diners.

[190] Restaria primerament que los béns dels dits pubils són en vàlua de sis-cents vint e dos sous dos diners, dels quals pervé a cascun pubil cent cinquantacinch sous sis diners, mealla, ${ }^{80}$ ço que ve a cascun pubil //f. 40//. E permanent ${ }^{81}$ demun venints a final expecificació en quina forma e manera

73 Tachado: dita.

74 Sobre línea: Sogorb.

75 Tachado: pujen.

76 Tachado: saig, co.

77 Tachado: per lo dit tudor en comunal profit.

78 Sobre línea: tres sous sis. Tachado debajo: cinch sous s.

79 Tachado debajo: cinch.

80 Tachado debajo: tres paveseres. Sobre línea: mealla. Tachado: com los dits DCXXII sous III diners sien en heretats e diners, per ço partim e divisim aquells en la forma següent.

81 Tachado: considerant que la dita fanqueada de terra dessús con. 
deieren ésser pagats a cascú dels dits pubils los dessús dits CLV sous VI diners, mealla.

[191] E considerants que la dita fanequada de terra dessús confrontada reebe gran deterioració e menys valença quant aquella fou partida ab l-altra fanequada que pervench a la mare dels dits pubils, en tant que si aquella se havie a vendre no valdrie los dohents sous en què fou stimada. E com arguix e tractement la dita Caterina Gómez qui per cert e designat salari per la cort de vos dit honrat justícia tatxat alimente e nodreix los dits Berthomico e Isabeleta menors se haje profert pendre e acceptar la dita fanequada de terra en paga e prorata de ço que deu haver de la dita alimentació en suma de CC sous.

[192] Per ço, per lo dit sguart e per ço encara que serà major profit de les altres pubiles menors que los dohents sous en diners que pervendran a la sua part ensemps ab l-altra quantitat ho sien smerçats ara de censal, per tal los dits béns partim e devisim en aquesta forma, ço és, que ajutgam e declaram a part dels dits Bertholomico e Isabeleta menors la dita fanequada de terra dessús confrontada, franqua e quita en suma de dohents sous. E la qual per lo dit tudor e curador en pagua e prorata de ço que deu haver la dita Caterina Gómez per la dessús dita alimen//f. 40v//tació (Jhesús) sie a aquella en lo dit preu donada ${ }^{82}$ e relexada $a^{83}$ tots los drets pertanyents als dits pubils.

[193] E dehim que lo dit tudor e curador sia tengut donar e paguar als propdits pubils menors compresos emperò los dessús mencionats cinquanta-huyt sous tres diners en usos propris de aquells, convertits cent onze sous hun diner. $^{84}$

[194] Ítem, pronunciam a la part ${ }^{85}$ de les dites Catalineta e Theresa, pubiles, primerament la dita vinya segons que dessús confrontada $a b$ lo dit càrrech de XXI sous censals en preu e stimació de cent sous, e lo restant a compliment de CCCXI sous I diner que serien do-cents onze sous, I, ${ }^{86}$ don en diners comptants los quals lo dit tudor e curador sia tengut tan prestament com pusca smerçar a censal en loch segur. Atres béns sitis ne movents sino los damunt dits ${ }^{87}$ nós dits en Gil de la Cerda e en Domingo el Toro no havem poscut atrobar ${ }^{88}$ pretanyents als dits pubils, dels quals hajam poscut fer

82 Tachado: relexada, venuda e. Sobre línea: donada e.

83 Añadido al margen izquierdo: aquestes quantitats són ja pagades als dits pubils per compensació feta ab la mare del alletament, compresos més et XI sous I diner.

84 Tachado: e mealla.

85 Al margen izquierdo: Catalina, Beleta, obivit.

86 Al margen izquierdo: CCXI s. I d.

87 Tachado: no trobam.

88 Tachado: atrobar dels quals. 
partició per la qual rahó nos feriem fer e enseguir vostres justs manaments, enxí com a jutges partidors damunt dits fahem a vos, dit molt honrat justícia, relació de totes e sengles coses dessús designades et mencionades axí ésser enseguides e passades si et segons que dessús és scrit et annotat.

//f. 41//

Jhesús

[195] Com en virtut de la propdita partició conste que als dits Berthomico e Isabeleta menors serien pervenguts CCCXI sous I diner, los quals revera ab gan cosa no hajen bastat ne bastaren a la alimentació de aquells de XXIIIen dia de abril, any XXXII que fou requesta tachació de provisió tro al primer dia de jener del any M CCCC XXXIIII que·s feu la propinserta relació, que són vint mesades, les quals a rahó de CCLXIIII sous per any segons fou tachat per l·onrat en Johan de Moros, justícia, ço és XII sous cascun mes al dit Berthomico e quatre diners cada dia a la dita Isabeleta, serien per tot les dites vint mesades CCCCXXXX sous. E com la part dels dits dos pubils no bastàs a tant, per ço la mare de aquells qui havia feta la dita alimentació solament ha haüds e reebuts de mi los dits CCCXI sous I diner, en aquesta manera, los CC sous en stimació de la dita fanequada de terra, e cin//f. 41v//quanta-cinch sous dos diners que li havia donats ab albarà reebut per Ramon del Ort, notari, a XXI d-octubre any M CCCC XXXII. E l-avanç que serien cinquanta-cinch sous onze diners doní a la dita mare dels pubils. Presents en Jacme Ximeno e Berthomeu Veyver e Ramon del Ort, notari, a XVIIII de jener any M CCCC XXXIIII. En axí que los dits dos pobils han ja despés tota lux part en axí que d·aquí avant no deig donar rahó a aquells de bésn alguns com no y haien.

//f. 42// [196] E com als dits Catalina e Beleta pubils encara exten béns, ço són la dita vinya de Navajas ab lo dit càrrech de XXI sous censals e do-cents onze sous hun diner en contants, per ço yo dit Johan Fretero, tudor e curador de aquelles, he continuat lo present capbreu de reebudes e dates en la forma següent.

\section{Reebudes.}

[197] Primerament, pos en reebuda que tinch de les dites Catalina e Beleta, pubiles, los dits CCXI sous I diners que a part de aquelles pervingueren a tenor de la dessús propinserta partició segons que en aquella se conté.

CCXI s. I.

//f. 42v// [198] Ítem, pos en reebuda XII sous tres diners de prorata de tres mesos de la trent de la vinya dels dits pubils, situada en Navajas, la qual atrentà Anthoni Aragonés a tres anys, per XXXXVIIII sous cascun any. E són aquests dit tres mesos si de la segona anyada el dit trent, los quals conegueren del primer dia de jener any XXX IIII que's feu la relació dels jutges, tro al fi de la dita segona anyada.

XXII s. III. 
[199] Ítem pos en reebuda del dit Anthoni Aragonés atrentador de la dita vinya en Navajas per la tercera e última anyada del dit trent que finí a quatre de abril, any M CCCC XXXV, quaranta-nou sous.

[200] Ítem pos en reebuda del dit Anthoni Aragonés per diverses llavors que falta a la dita vinya, les quals foren tachades per la cort en XXVII.

XXXXVIIII s.

XVII s.

//f. 43// [201] Ítem pos en reebuda de XIII cànters de vi qui ixqueren de la dita vinya dels pubils en 1.any M CCCC XXXV que jàtsia subastada no $s \cdot i$ troba atrentador, los quals dits XIII ${ }^{89}$ cànters se veneren a dos sous, que pujen XXVI.

[202] Ítem pos en reebuda de cinquanta cànters que ixqueren de vi en la dita vinya en 1.any M CCCC trenta-sis, los quals se veneren a diversos preus ço és a VIII et a VI diners el cànter, e ixqueren per tot trenta sous.

[203] Ítem pos en reebuda del vi que ixqué de la dita vinya en 1·any M CCCC XXXVII que foren cinquanta cànters, los quals se veneren a for de hun sou lo cànter, que pujen.

XXVIs.

XXX s.

L s.

//f. 43v// [204] Ítem pos en reebuda del vi de la dita vinya del any M CCCC XXXVIII que foren XVIII cànters, los quals se veneren a for de XVI diners per cànter, pujen XXIIII sous.

[205] Ítem pos en reebuda del vi de la dita vinya del any M CCCC XXX VIIII e foren setze cànters, los quals se veneren a for de XVI diners lo cànter, que pujen XXIII sous.

[206] Ítem pos en reebuda per lo guany que ha fet los diners dels dits pubils tro que la dita Catalina ha pres son marit, vint sous.

CCCCLXXIII s. IIII d.

//f. 44 a f. $44 \mathrm{v}$, en blanco//

//f. $45 / /$

Jhesús

[207] Dates fetes per mi Johan Fretero, tudor e curador de les persones e béns de Catalina e Beleta, pubils, fills e hereus d·en Pere Martínez, texedor vehí

89 Tachado: $X X$. 
quondam de la ciutat de Sogorb, après que hagueren partit ab Berthomico e Isabeleta, germans lurs, segons appar per lo present libre. E les presents dates comencen en jener, any M CCCC XXXIIII, les quals són pro ut secuntur:

[208] Primerament pos en data al discret en Jacme Dassio, clergue beneficiat del benefici al qual la vinya de les dites pubiles situada en Navajas fa XXI sous censals a Nadal e a sent Johan, any XXXIIII, appar per albarà scrit de sa mà en lo dit any.

[209] Ítem pos en data al dit en Jacme Dassio beneficiat sobredit per la pagua de Nadal entrant, any XXXV, deu sous sis diners, segons appar per albarà scrit de sa mà en lo dit any.

[210] Ítem pos en data al discret en Jacme Dassio, beneficiat dessús dit, per lo dit cens de la vinya de Navajes e per la pagua de sent Johan, any M CCCC XXXV, deu sous sis diners, segons appar per albarà scrit de sa mà a $\mathrm{XX}$ de setembre any M CCCC XXXV.

\section{(Any M CCCC XXXVI)}

[211] Ítem pos en data al sobredit mossén Jacme Dassio per lo dit cens de la vinya e per la pagua de Nadal, any XXXVI, deu sous sis diners segons appar per albarà scrit de mà de X s. VI. Pascual de Coria, procurador seu, a quatre de febrer any XXXVI.

//f. 46// [212] Ítem pos en data al mateix en Jacme Dassio beneficat, per rahó del dit cens e per la pagua de sent Johan, any XXXVI, segons appar per albarà scrit de sa mà a XXV d·agost any sobredit, deu sous sis diners.

\section{(Any M CCCC XXXVII)}

[213] Ítem pos en data al damunt dit en Jacme Dassio per lo cens de la dita vinya e per la pagua de Nadal, any XXXVII, deu sous sis diners segons appar per albarà scrit de sa mà a XVIII de febrer any M CCCC XXXVII.

[214] Ítem pos en data al dit en Jacme Dassio per rahó del cens de la dita vinya de Navajas e per la pagua de sent Johan, 
any XXXVII, deu sous sis diners, segons appar per albarà scrit de sa mà en lo dit any.

[215] Ítem pos en data al damunt dit en Jacme Dassio beneficiat damunt dit, per lo cens de la damunt dita vinya e per les pagues de Nadal e sent Johan, any M CCCC XXXVIII, vint e hun sou, segons appar per albarà scrit de sa mà $\mathrm{a} V$ XXI s. de febrer.

\section{(Any M CCCC XXXVIIII)}

[216] Ítem pos en data a·n Pascual de Coria, col·lector del benifet damunt, per lo fill d·en Johan del Peral novament provehit del dit benifet, per decés del sobredit mossén Jacme Dassio, e per la pagua de Nadal, any XXXVIIII, deu sous sis diners, segons appar per albarà scrit de mà del dit Pascual, any XXXVIIII a XI de maig.

//f. 47// [217] Ítem pos en data al dit en Pascual de Coria, col-lector sobredit, per la pagua de sent Johan, any M CCCC XXX VIIII, per lo cens de la dita vinya, deu sous sis diners, segons appar per albarà scrit de sa mà a XXX de agost, any sobredit.

\section{(Any M CCCC XXXX)}

[218] Ítem pos en data al dit en Pascual de Coria, col·lector sobredit, X sous VI diners, en, e per la pagua de Nadal, any $\mathrm{XXXX}$, per rahó del cens de la dita vinya segons appar per albarà scrit.

X s. VI.

[219] Ítem pos en data al damunt dit en Pascual de Coria, col·lector que dessús, per la pagua de sent Johan, any XXXX, deu sous sis diners, segons appar per albarà scrit de sa mà, a XXX de juliol any M CCCC XXXX.

//f. 47v// Seguexen-se les pagues de la peyta.

[220] Primerament pos en data a Anthon Aragonés, col·lector de la peyta any XXXIIII, per la peyta de la dita vinya de les pubiles, tres sous segons appar per albarà scrit de sa mà a XIII de setembre, any XXXIIII.

III s.

[221] Ítem pos en data al dit Anthon Aragonés, col·lector de la dita peyta en lo any XXXV, altres tres sous per la peyta 
de la dita vinya segons appar per albarà de sa mà scrit a XIII de juny any M CCCC XXXVI.

[222] Ítem, pos en data a·n Martí de Gurrea, col·lector de la peyta $1 \cdot$ any XXXVI per la peyta de les dites pubiles, tres sous segons appar per albarà de sa mà scrit, a VI de maig any M CCCC XXXVI

//f. 48// [223] Ítem pos en data a·n Benedito Consuelta, col·lector de la peyta any M CCCC XXXVII, tres sous per lo dit any, ço és per la peyta de la vinya tres sous segons appar per albarà scrit de sa mà a XXI de maig, any $\mathrm{M} \mathrm{CCCC}$ XXXVII.

[224] Ítem pos en data a·n Anthoni Aragonés ${ }^{90}$, col·lector de la peyta any XXXVIII, tres sous per la peyta de la dita vinya, any sobredit, segons appar per albarà scrit.

[225] Ítem, pos en data a Jaume Latonda, col·lector de la peyta del any XXXVIIII ${ }^{\circ}$ quatre sous sis $^{91}$ per la peyta de la vinya de les dites pubilles segons appar per albarà scrit de sa mà, a XIII de febrer any M CCCC XXXX.

//f. 48v// [226] Ítem pos en data al honrat en Pere Dassio, siser de la sisa de la peça que pres la mare dels dits pubils, e per les almonedes feytes dels béns mobles, ço és per la part pertanyent a les dites pubiles, sis sous, segons appar per albarà scrit de sa pròpria mà, a XVIIII de juny any M CCCC XXXIIII.

[227] Ítem pos en data al discret en Bernat Rosselló, notari, per provehir la requesta dels jutges partidors asignats derrerament a partir los béns entre los pubils, e per la relació de aquells, tres sous sis diners, segons appar per albarà scrit de mà del discret en Jacme Pexó ${ }^{92}$, notari, a XXIII de dehembre, any M CCCC trenta-quatre.

[228] Ítem pos en data a Daniel Polo, corredor, tres sous sis diners, per rahó de sos treballs de vendre //f. 49// la taça
III s.

III s.

III s.

III s.

IIII s. VI.

VI s.

III s. VI. 
$\mathrm{d} \cdot \operatorname{argent}$ en los primers comptes dalt mencionada, e per còrrer e subastar lo trent de la vinya de les dites pubiles, en la qual no $s \cdot i$ trobà atrentador segons appar per albarà scrit de mà de Ramon del Ort, notari, a VI de setembre any M CCCC XXXV.

III s. VI. ...s. VI.

//f. 49v// (Despeses fetes en cultivar la vinya e en venemar, e loguer de vexells)

\section{(Any XXXV)}

[230] Ítem pos en data que en $1 \cdot$ any M CCCC XXXV fiu reguar la vinya, costà.

[231] Ítem, la fiu scardar, costà.

[232] Ítem, en lo dit any costà de venemar la dita vinya.

[233] Ítem, de acarrejar la venema.

[234] Ítem, de pisar tres càrregues de venema.

[235] Ítem, loguer de cub e freguar aquel.

[236] Ítem, loguer de una jarra.

[237] Ítem, en lo dit any M CCCC XXXV fiu podar la vinya, la qual podà Bernat $\mathrm{d} \cdot$ Estella, tres dies a rahó de dos sous tres diners, e ab vi e pitança, puje per tot VI sous VIIII diners.

[238] Ítem, exarmentar hun home.

//f. 50// [239] Ítem, doní a Miquel Gascon, de reguar la dita vinya.

[240] Ítem, en lo dit any fiu cavar la dita vinya, entraren-hi quinze peons, los quals loguà Andrés de Cutanda, a rahó de dos sous set diners, e ab vi e pitança, pujà per tot XXXVIII sous XI diners.

[241] Ítem, a hun fadrí qui cavà les orellades e nedejà les céquies per tres dies, a rahó de hun sou cascun dia, tres sous. I s. VI.

\author{
II s. \\ I s. II. \\ I s. VI. \\ ...s. III. \\ III s. VI. \\ I s.
VI s. VIIII.
I s. VI. \\ I s. VIII.
}

XXXVIII s. XI

III s. 
[242] Ítem, pos en data que doní a tres hòmens de podar la vinya, ab vi e pintança, pujà sis sous sis diners.

VI s. VI.

//f. 50v// [243] Ítem pos en data a hun peon qui scardà la vinya de les dites pubiles.

[244] Ítem, pos en data que paguí a un home qui reguà la dita vinya.

[245] Ítem, en lo any M CCCC XXXVI fiu cavar la dita vinya, entraren-hi dotze peons, a rahó de dos sous sis diners per peó, trenta sous, e tres sous de pitança e vi, que són per tot XXXIII sous.

[246] Ítem en lo dit any paguí de loguer de un cup per a la venema de la dita vinya, per cinch sous.

[247] Ítem, paguí a un moro de venemar la venema e d·acarrejar aquella, per tot sis sous sis diners.

[248] Ítem pos en data que paguí de loguer de dos parells de portadores per a venemar, hun sou.

[249] Ítem, pos en data de fer freguar lo cup ab dos dinés de aygua.

//f. 51// [250] Ítem pos en data que paguí de pisar la venema de les dites pubiles, nou diners.

...s. VIIII.

[251] Ítem, pos en data que paguí per lo loguer de la cuba per al vi de les dites pubiles V sous VIII diners.

[252] Ítem, més que paguí a hun home qui acarrejà lo vi del cup a la cuba, e ab lo treball depuys del vendre, per tot dos sous.

\section{(Any M CCCC XXXVII)}

[253] Primerament paguí a tres peons de podar la vinya, ab vi e pitança, sis sous sis diners.

VI s. VI.

[254] Ítem, pos en data a hun home qui scardà la dita vinya, ab vi e pitança, dos sous III diners.

II s. III.

[255] Ítem, més paguí a un home de reguar la dita vinya, dos II $\mathrm{s}$. 
//f. 51v// [256] Ítem, pos en data que paguí de loguer del cup per a la venema de les dites pubiles, ab freguar e aygua, cinch sous VIII diners.

[257] Ítem, aprés paguí a dos homes qui venemaren la dita vinya, XV diners a cascú, e IIII diners de vi e pitança, que són per tot dos sous deu diners.

[258] Ítem, paguí de pisar la dita venema ab loguer de dos parells de portadores, hun sou VIIII diners.

V s. VIII.

II s. X.

I s. VIIII.

[259] Ítem, paguí de loguer de una cuba per al dit vi de les dites pubiles, cinch sous e VIII diners de freguar la dita cuba e aygua. E un sou de traure 1 vi, que són per tot VI sous VIII diners.

VI s. VIII.

\section{(Any M CCCC XXXVIII)}

[260] Ítem, paguí a Andrés de Cutanda de nedejar la céquia qui //f. 52// confronta ab la vinya de les dites pubiles, ço és per dos jornals ab vi e pitança, quatre sous sis diners.

[261] Ítem, paguí de venemar la vinya dos sous, e de tallar la venema, un sou. E de pisar, sis93 diners. E quatre diners de loguer de portadores que són per tot tres sous deu diners.

[262] Ítem, paguí de lloguer de cub,94 tres sous. E de freguar sis diners.

[263] Ítem, paguí a Bernat d·Estella de podar la dita vinya, ab vi e pitança, sis sous nou diners.

[264] Ítem, lloguí una jarra per a tenir lo vi, per un sou sis diners.

\section{(Any M CCCC XXX VIIII $\left.{ }^{\circ}\right)$}

[265] Ítem, loguí un cub per tres sous, e paguí de aygua e freguar, sis diners.

//f. 52v// [266] Ítem, loguí un parell de portadores per a venemar la vinya del pubil, per sis diners. 
[267] Ítem, paguí a un venemador ab pitança, hun sou set $\mid$ I s. VII. diners.

[268] Ítem, paguí a un acarrejador dos sous.

II s.

[269] Ítem, paguí de pisar tres càrregues e miga, tres diners. $\quad$...s. III.

[270] Ítem, provisió al acarrejador, sis diners.

[271] Ítem, loguí una jarra per a metre lo vi, dihuyt diners, e tres diners de llavar, que són.

\section{(Any M CCCC XXXX)}

[272] Ítem, loguí tres peons per a podar la vinya, a rahó de dos sous. E nou diners de vi e pitança, que són per tot sis sous nou diners.

[273] Ítem, pos en data que deig haver de mon salari per regir e adminstrar la present tutela e cura, sixanta sous.

VI s. VIIII.

LX s.

//f. 53r// [274] Ítem, doní e paguí a la dita Catalina, muller d·en Miquel de Carrion, e al dit son marit, per la part a la dita Catalina pertanyent dels damunt dits béns, axí dels haguts a aquella per son pare, com de la part que li toqua en la part de Beleta, defuncta, cent sous segons appar per albarà scrit de mà del discret mossén Johan Navarro, prevere, a tres de maig any MCCCCXXXX, C sous.

\section{6. Índice onomástico y toponímico}

Alloça, Martí d. Vecino de Segorbe, juez partidor: 3, 12, 80 .

Aragonés, Antoni. Mayor, vecino de Segorbe, arrendador viña, labrador: 8, 136, 141, 198, 199, 200.

Aragonés, Antoni. Menor, colector de la pecha: 171, 220, 221, 224.

Aragonés, Joan. Pelaire, colector del morabatín: 170.

Belmunt, Joan de. Corredor: 167.

Berthomeu (Berthomico, Bertholomico). Hijo y heredero de Pere Martínez: 1, 8, 12 , 157, 166, 179, 182, 189, 191, 194, 195, 207.

Beyites, Antoni: 168 .

CAMÍ REAL: 6, 73, 186.

CAMPO.

-Partida de la huerta de Segorbe: 76.

-Cabeçadas del: 171.

Carrión, Miquel de. Marido de Catalina: 274.

Catalina (Caterineta, Catalineta). Hija y heredera de Pere Martínez, esposa de Miquel de Carrión: 1, 12, 102, 182, 194, 196, 197, 206, 207, 274. 
Cerda, Gil de la. Vecino de Segorbe, juez partidor de bienes, labrador: 3, 12, 80, 176, 181, 182, 194.

Cerveró, Paricio. Presbítero: 6,73, 186.

Consuelta, Benedito. Colector de la pecha: 223.

Coria, Pasqual de. Colector de censales de beneficio: 156, 162, 211, 216, 217, 218 , 219.

Cuqualó, Eximeno. Ciudadano de Segorbe: 73, 165.

Cutanda, Andrés: 129, 240, 260.

Cutanda, Paricio: 76.

Dassio, Jaume. Clérigo beneficiado: 163, 172, 208, 209, 210, 211 , 212, 213, 214, 215 , 216.

Dassio, Pere. Sisero: 173, 226.

Descó, Ximeno. Labrador vecino de Segorbe, arrendador de tierra: 9, 143.

Estella, Bernat de: 237, 263.

Ferrández, Joan. Hornero vecino de Segorbe: 79, 133.

Fretero, Joan. Tejedor vecino de Segorbe, tutor y curador testamentario: 1, 12, 102, 131, 149, 178, 182, 185, 196, 207.

Gascón, Miquel: 239.

Gerart, Jaume. Notario: 78.

Gómez, Catalina (Guómez, Caterina). Esposa de Pere Martínez, madre de los pubiles: 5, 9, 10, 12, 70, 71, 74, 75, 77, 78, 79, 133, 137, 157, 159, 183, 184, 187, 191, 192. Gurrea, Martí de. Colector pecha: 222.

Isabeleta (Ysabeleta). Hija y heredera de Pere Martínez: 1, 8, 12, 157, 166, 179, 182, 189, 191, 192, 195, 207.

Just, Miquel. Preboste de la cofradía de san Blas de Segorbe: 164.

LAGUNAS. Camino que va a, y partida de la huerta de Segorbe: 77, 78 .

Latonda, Jaume. Colector pecha: 225, 229.

López Cabrit, Bernat: 78.

Mançana, Joan. Nuncio de la corte, corredor: 6, 9, 151, 153, 160.

Martínez, Pere (Pero). Tejedor, difunto vecino de Segorbe, cofrade de san Blas: 1, 2, 10, 12, 71, 75, 78, 102, 131, 149, 154, 159, 164, 182, 183, 207.

Montón, En. Honorable: 163.

Moros, Joan de. Justicia de Segorbe: 5, 6, 8, 9, 12, 195.

NAVAJAS (Navajes). Partida de la huerta de Segorbe: 6, 73, 106, 136, 138, 141, 147, $162,163,165,185,186,196,198,199,208,210,214$.

Navarro, Joan. Presbítero: 274.

Noguera, Joan de: 9, 74, 77, 187.

Ort, Pere del: 162.

Ort, Ramón del. Notario: 2, 4, 5, 132, 139, 154, 157, 159, 161, 167, 169, 171, 175 , 176, 182, 184, 195, 228.

Peral, Joan del: 216. 
Pérez, Domingo. Tejedor: 78.

Pexó, Jaume. Notario: 155, 277.

Polo, Daniel. Corredor: 228.

Riglos, Joan de: 76.

Rosselló, Bernat. Notario, escribano de la corte: 6, 9, 152, 153, 160, 166, 174, 177, 227.

Rosselló, Bertomeu: 6, 73, 186.

Ruvio, Joan. Vecino de Segorbe: 168.

Sánchez de Uncastiello, Joan: 76.

SEU de la ciudad de Segorbe: 73, 78, 186.

Teresa (Theresa, Teresuca). Hija y heredera de Pere Martínez: 1, 12, 102, 182, 194.

También llamada Beleta:196, 197, 207, 274.

Toro, Domingo el. Tejedor vecino de Segorbe, albacea testamentario: 2, 176, 181, $182,194$.

Tortajada, Joan de. Acequiero de la fuente: 229.

UTRIELLAS. Partida de la huerta de Segorbe: 7, 9, 74, 77, 80, 135, 143, 147, 185, 187.

Veyver, Bertomeu: 195.

Vicent, Lluis: 156, 162.

Vilanova, Joan de: 9, 74, 187.

Ximeno, Jaume: 195.

\section{Referencias bibliográficas}

APARICI MARTí, Joaquín (2001), El Alto Palancia como polo de desarrollo económico en el siglo XV. El sector de la manufactura textil. Segorbe, Ayuntamiento de Segorbe.

APARICI MARTí, Joaquín y Germán NAVARRo ESPINACH (1997), «El libro memorial de la tutela del tejedor Joan Fretero (Segorbe 1432-1440)», Estudis Castellonencs, 7: 231-264.

APARICI MARTí, Joaquín y Germán NAVARRO ESPINACH (2010), «Considerada encara la pocha edat e ignoncència... Los primeros años de vida para los niños del siglo XV», Millars, Espai i Història, 33: 55-74.

CACHÓN RODRÍGUEZ, Lorenzo (1989), ¿Movilidad social o trayectorias de clase? Elementos para una crítica de la sociología de la movilidad social. Madrid, CISSiglo XXI.

CRuselles Gómez, José María (1986), «Familia y promoción social: los Lopiç de Valencia (1448-1493)», Estudis Castellonencs, 3: 355-380.

CRuselles GómEZ, José María (1989), «Maestros, escuelas urbanas y clientela en la ciudad de Valencia a finales de la Edad Media», Estudis, 15: 9-44.

CRuselles GóMEZ, José María (1990), «Movilidad social y estrategias familiares en el medio urbano bajomedieval», Millars, 13: 87-94. 
GODELIER, Maurice (1990), Lo ideal y lo material. Madrid, Taurus.

Guerrero Carot, Francisco José y Francisco M. Gimeno Blay (1986), Archivo Histórico Municipal de Segorbe (1286-1910). Valencia, Dirección General de Cultura.

GuINOT RodRíGuEZ, Enric y Antoni Furió I DiEGO (1980), «Un exemple d'economia domèstica de principis del XV̀̀ . L'administració d'una tutela. Sueca 1412-1427», Quaderns de Cultura de Sueca, 1: 11-46.

Hinojosa Montalvo, José (2005), «San Blas, un santo universal para una cofradía medieval en Segorbe», Boletín de la Sociedad Castellonense de Cultura, 81: 323 351.

IGUAL LUIS, David (1992), «L'escriptura del comerç a la baixa Edat Mitjana. Una font material d'estudi», Butlletí de l'Associació Arqueològica de Castelló, 12: 67-76.

IRADIEL MURUGARREN, Paulino (1986), «Familia y función económica de la mujer en actividades no agrarias.» En La condición de la mujer en la Edad Media, Madrid, Universidad Complutense de Madrid: 223-260.

IRADIEL MURUGARREN, Paulino (1993), «Economia y sociedad feudo-señorial: cuestiones de método y de la historiografía medieval.» En Eliseo Serrano Martín y Esteban Sarasa Sánchez, coords., Señorío y feudalismo en la Península Ibérica, ss. XII-XIX. Zaragoza, Institución Fernando El Católico. Vol. 1: 17-50.

NAVARRO ESPINACH, Germán (1992), «El corder Joan Borrell (1467). Estudi de cultura material», Butlletí de l'Associació Arqueològica de Castelló, 12 : 77-96.

NAVARRO EsPinACH, Germán (1993), «L'artisanat de la soie à Valence à la fin du Moyen Age», Razo. Cahiers du Centre d'Etudes Médiévales de Nice, 14 : 163175.

NAVARRO ESPINACH, Germán (2004), «Las etapas de la vida en las familias artesanas de Aragón y Valencia durante el siglo XV», Aragón en la Edad Media, 18: 203 244.

NAVARRO ESPINACH, Germán (2005), «Los artesanos aragoneses y valencianos del siglo XV. Prácticas sociales comparadas buscando un guión de vida.» En Rafael Narbona Vizcaíno, coord., La Mediterrània de la Corona d'Aragó, segles XIII-XVI; y VII Centenari de la Sentència Arbitral de Torrellas, 1304-2004. Actes del XVIII Congrés d'Història de la Corona d'Aragó. València, Universitat de Valéncia. Vol. 1: 1077-1088. 
